\title{
The vertical distribution of ozone instantaneous radiative forcing from satellite and chemistry climate models
}

\author{
A. M. Aghedo, ${ }^{1}$ K. W. Bowman, ${ }^{1}$ H. M. Worden, ${ }^{2}$ S. S. Kulawik, ${ }^{1}$ D. T. Shindell, ${ }^{3}$ \\ J. F. Lamarque, ${ }^{2}$ G. Faluvegi, ${ }^{3}$ M. Parrington, ${ }^{4,5}$ D. B. A. Jones, ${ }^{4}$ and S. Rast ${ }^{6}$ \\ Received 23 March 2010; revised 5 October 2010; accepted 3 November 2010; published 13 January 2011.
}

[1] We evaluate the instantaneous radiative forcing (IRF) of tropospheric ozone predicted by four state-of-the-art global chemistry climate models (AM2-Chem, CAM-Chem, ECHAM5-MOZ, and GISS-PUCCINI) against ozone distribution observed from the NASA Tropospheric Emission Spectrometer (TES) during August 2006. The IRF is computed through the application of an observationally constrained instantaneous radiative forcing kernels (IRFK) to the difference between TES and model-predicted ozone. The IRFK represent the sensitivity of outgoing longwave radiation to the vertical and spatial distribution of ozone under all-sky condition. Through this technique, we find total tropospheric IRF biases from -0.4 to $+0.7 \mathrm{~W} / \mathrm{m}^{2}$ over large regions within the tropics and midlatitudes, due to ozone differences over the region in the lower and middle troposphere, enhanced by persistent bias in the upper troposphere-lower stratospheric region. The zonal mean biases also range from -30 to $+50 \mathrm{~mW} / \mathrm{m}^{2}$ for the models. However, the ensemble mean total tropospheric IRF bias is less than $0.2 \mathrm{~W} / \mathrm{m}^{2}$ within the entire troposphere.

Citation: Aghedo, A. M., K. W. Bowman, H. M. Worden, S. S. Kulawik, D. T. Shindell, J. F. Lamarque, G. Faluvegi, M. Parrington, D. B. A. Jones, and S. Rast (2011), The vertical distribution of ozone instantaneous radiative forcing from satellite and chemistry climate models, J. Geophys. Res., 116, D01305, doi:10.1029/2010JD014243.

\section{Introduction}

[2] Tropospheric ozone is important to both atmospheric chemistry and climate through its role as a primary oxidant, air pollutant and as a greenhouse gas. Ozone in the troposphere is produced by photochemical oxidation of its precursors, namely carbon monoxide $(\mathrm{CO})$, methane $\left(\mathrm{CH}_{4}\right)$ and nonmethane hydrocarbons (NMHC), in the presence of nitrogen oxides $\left(\mathrm{NO}_{x}=\mathrm{NO}+\mathrm{NO}_{2}\right)$. Tropospheric ozone concentration is also modulated by the downward transport from the stratosphere [e.g., Wang et al., 1998]. Since the preindustrial time, there has been a large increase in anthropogenic emissions of ozone precursors, leading to an increase in tropospheric ozone concentration worldwide [e.g., Volz and Kley, 1988; Marenco et al., 1994; Wang and Jacob, 1998]. Based on the multimodel median, the radiative forcing of anthropogenically produced tropospheric ozone presented in the fourth assessment report of the IPCC,

\footnotetext{
${ }^{1}$ Jet Propulsion Laboratory, California Institute of Technology, Pasadena, California, USA.

${ }^{2}$ Atmospheric Chemistry Division, National Center for Atmospheric Research, Boulder, Colorado, USA.

${ }^{3}$ NASA Goddard Institute for Space Studies, New York, New York, USA.

${ }^{4}$ Department of Physics, University of Toronto, Toronto, Canada.

${ }^{5}$ Now at School of Geosciences, University of Edinburgh, Edinburgh, United Kingdom.

${ }^{6}$ Max Planck Institute for Meteorology, Hamburg, Germany.

Copyright 2011 by the American Geophysical Union. 0148-0227/11/2010JD014243
}

Climate Change 2007 [Forster et al., 2007] is $0.35 \mathrm{~W} / \mathrm{m}^{2}$ (with a spread of between 0.25 and $0.65 \mathrm{~W} / \mathrm{m}^{2}$ ), making the greenhouse effect of tropospheric ozone the third largest, following carbon dioxide and methane.

[3] The traditional way for calculating the radiative forcing of tropospheric ozone from models follows two steps: the first step is to calculate the change in ozone concentration due to changes in ozone precursor emissions and stratosphere-troposphere exchange. This is straightforward in chemical transport models (CTMs) and chemistry climate models, because they accept as input bottom-up emissions of ozone precursors for preindustrial (usually taken as year 1850s) and present day (usually year 2000s) in separate simulations to calculate the respective tropospheric ozone concentrations. There are, however, large uncertainties in emissions of ozone precursors for preindustrial conditions [Mickley et al., 2001]. The second step is to calculate the radiative forcing due to the change in present-day ozone relative to the preindustrial era by using a radiative transfer model (RTM). Two popular methods exist for the radiative forcing calculation within a RTM. The first method follows the definition of Ramaswamy et al. [2001], which allows the stratospheric temperature to readjust to equilibrium following radiative perturbation, while the second method is called the instantaneous radiative forcing (IRF), which calculates the net flux, either at the tropopause or at the top of the atmosphere (TOA), without allowing stratospheric temperature to adjust. In addition to the uncertainty in the emissions, there are additional uncertainties associated with 
the RTM used in the radiative forcing calculation [e.g., Gauss et al., 2006], and the definition of the tropopause adopted in models (e.g., "flat tropopause" set at 100, 150 or $200 \mathrm{hPa}$, "zonally invariant and linear with latitude tropopause," as used by Hansen et al. [1997] and Naik et al. [2005], "chemical tropopause" using 150 ppbv ozone level, and the thermal tropopause which follows the definition of the World Meteorological Organization [1957]). In general, the difference in the tropospheric ozone IRF forcing calculated at the tropopause is anywhere between 10 and $22 \%$ larger than the stratospheric adjusted forcing [Haywood et al., 1998; Gauss et al., 2006; Forster et al., 2007], depending on the model. Using either of the radiative forcing methods, the difference of the total forcing (shortwave and longwave) generated by the present-day and preindustrial ozone gives the radiative forcing of tropospheric ozone since the preindustrial era [e.g., Berntsen et al., 2000; Hauglustaine and Brasseur, 2001; Mickley et al., 2001; Shindell et al., 2003; Gauss et al., 2006].

[4] The estimates of tropospheric ozone radiative forcing reported in the IPCC assessment reports are calculated as described above and have only indirectly benefited from remotely sensed observations of tropospheric ozone, which have become available in the last three decades [Fishman et al., 2008, and references therein]. Recently, Worden et al. [2008] used the reduction in clear-sky outgoing longwave radiation (OLR) due to ozone, directly observed from Tropospheric Emission Spectrometer (TES) to estimate the greenhouse effect of tropospheric ozone over the tropical and midlatitudes ocean in 2006. Another less direct method based on combining several satellite products and assimilated meteorology to derive an estimate of the net change in radiance at the tropopause produced by tropospheric ozone was also presented by Joiner et al. [2009].

[5] The accurate estimation of tropospheric ozone radiative forcing is contingent on the ability of models to simulate the spatial and vertical distribution of ozone within the entire troposphere [Lacis et al., 1990]. This study uses spectrally resolved OLR sensitivity from TES under all-sky condition (which we referred to as instantaneous radiative forcing kernels, IRFK (H. M. Worden et al., Observed instantaneous radiative kernels for tropospheric ozone from the NASA Aura Tropospheric Emission Spectrometer (TES), submitted to Journal of Geophysical Research, 2010)), ozone data retrieved from TES, and the ozone concentrations from four global chemistry climate models to derive the vertically resolved instantaneous radiative forcing bias of tropospheric ozone in August 2006. The observationally constrained IRFK are computed from the sensitivity of the top of the atmosphere radiances to ozone vertical distribution, which are called Jacobians, as a part of the ozone retrieval process for TES [Clough et al., 2006]. The IRFK present a new and consistent observationally based method for evaluating the instantaneous radiative impact of ozone from chemistry climate models. This approach is similar to the definition and application of the radiative kernels by Soden et al. [2008], but is directly constrained by satellite measurements. The instantaneous radiative forcing derived by applying TES IRFK is different from the tropospheric ozone radiative forcing presented in the IPCC [Forster et al., 2007], which includes both shortwave and longwave forcing of changes in tropospheric ozone due to anthropogenic emissions from preindustrial to present day. Our definition is consistent with the fundamental definition of radiative forcing which calculates the change in the radiative fluxes at the top of the atmosphere [e.g., Ramanathan et al., 1989].

[6] This paper shows the potential of global satellite observations and observationally derived IRFK to quantify the impact of discrepancies in climate model-predicted ozone on instantaneous radiative forcing. A brief description of each model is provided in section 2 . In section 3, we discuss TES data and observation operators and how they are applied to model predictions in order to provide a consistent comparison between TES and each of the models. Also in section 3, we present the derivation of the IRFK. In section 4, we evaluate the models tropospheric ozone against TES. The instantaneous radiative forcing is presented in section 5. The conclusions and summary are in section 6 .

\section{Model Descriptions}

[7] This study employs four global chemistry climate models (CCM) to simulate the ozone concentration of August 2006. The models include AM2-Chem, CAMChem, ECHAM5-MOZ and GISS-PUCCINI. Each of the models is briefly described below. We decided that all modeling groups should use their own emissions inventories because these emissions have been tested for the models. However, in order to capture the dynamics and the synoptic features of year 2006, the simulated meteorology of each model was constrained by prescribed assimilated analysis data, except the CAM-Chem model, which uses prescribed sea surface temperatures and sea ice fields from the Hadley Centre [Rayner et al., 2003]. Table 1 provides the summary of model configurations.

\subsection{The AM2-Chem Model}

[8] The AM2-Chem model contains the general circulation model AM2 [GFDL GAMDT, 2003] with reduced tropospheric chemistry of MOZART-2 chemical transport model [Horowitz et al., 2003]. The AM2-Chem has only tropospheric chemistry. The model has a horizontal resolution of $2^{\circ}$ latitude by $2.5^{\circ}$ longitude, and 24 vertical levels from the surface to approximately $3 \mathrm{hPa}$. The model dynamics was constrained by nudging to reanalysis data [Kalnay et al., 1996] from the National Centers for Environmental Prediction (NCEP).

[9] The model tropospheric chemistry consists of ozone$\mathrm{NO}_{x}$-CO-hydrocarbon, and sulfate and carbonaceous aerosols. The chemical reactions involving isoprene oxidation is simplified to approximate the production of ozone and peroxyacetyl nitrate (PAN) from isoprene. The model excludes higher-order NMHC. The model has 41 chemical species and 100 chemical reactions. The emissions used in the model simulation are the same as used in the MOZART2 CTM fully described by Horowitz et al. [2003], and represent emissions of the 1990s, with the exception of lightning $\mathrm{NO}_{x}$, which is parameterized within the model based on the work by Price et al. [1997], with the vertical distribution based on the work of Pickering et al. [1998]. The model has no stratospheric chemistry, but stratospheric ozone distribution is represented by a HALOE climatology 
[Randel and $W u, 1999]$, while stratospheric distributions of $\mathrm{CO}, \mathrm{NO}_{x}, \mathrm{HNO}_{3}, \mathrm{~N}_{2} \mathrm{O}$, and $\mathrm{N}_{2} \mathrm{O}_{5}$ are relaxed to climatological values from the Study of Transport and chemical Reactions in the Stratosphere (STARS) model [Brasseur et al., 1997].

[10] In order to understand the influence of assimilation of observation data on tropospheric ozone IRF, we also present results from AM2-Chem configuration with assimilation of TES ozone and CO [Parrington et al., 2008], we would henceforth refer to this version as "AM2-Chem-assim." AM2-Chem and AM2-Chem-assim ozone fields used in this study were evaluated over North America against INTEX Ozonesonde Network Study 2006 (IONS-06) [Thompson et al., 2007a, 2007b]. In comparison with IONS-06 data, AM2-Chem mean profile ozone shows about $40 \%$ negative bias within the free troposphere (i.e., 700-200 hPa), and up to $15 \%$ and $60 \%$ positive bias at the upper troposphere and the boundary layer, respectively. The assimilation of TES into the model led to an improvement of the low bias in the free troposphere from $40 \%$ to $10 \%$ [Parrington et al., 2008].

\subsection{The CAM-Chem Model}

[11] The CAM-Chem model is based on the Community Atmosphere Model version 3.5 [Collins et al., 2006]. The chemistry is as described by Lamarque et al. [2008]. The CAM-Chem model has a horizontal resolution of $1.9^{\circ}$ latitude by $2.5^{\circ}$ longitude, and 26 vertical levels from the surface to approximately $40 \mathrm{~km}(\sim 4 \mathrm{hPa})$. This model version includes both tropospheric and stratospheric chemistry. Internally generated meteorology uses the observed sea surface temperature and sea ice distributions from Rayner et al. [2003] as boundary conditions. No relaxation of the dynamic state toward meteorological forecast data is performed.

[12] The chemical mechanism used in this study is formulated to provide a representation of both tropospheric and stratospheric chemistry [Lamarque et al., 2008]. Specifically, to successfully simulate the chemistry above $100 \mathrm{hPa}$, a representation of stratospheric chemistry was included, as described by Lamarque et al. [2008] (including polar ozone loss associated with stratospheric clouds) from version 3 of MOZART [Kinnison et al., 2007]. The tropospheric chemistry contains the standard methane reactions of MOZART 2 [Horowitz et al., 2003] and a reduced nonmethane hydrocarbon scheme similar to Carbon Bond Mechanism-4 [Houweling et al., 1998]. This reduced volatile organic compounds chemistry was extended to include isoprene and terpene oxidation. Also the chemical kinetic rates were updated from those of JPL-2002 [Sander et al., 2003] to JPL-2006 [Sander et al., 2006]. Because of a significant underestimation of the formation of peroxyacetyl nitrate (PAN) due to the Houweling et al. [1998] chemical scheme, the scheme was modified to include PAN formation from reaction of $\mathrm{OH}$ with aldehydes. This leads to a very reasonable simulation of PAN and other important chemical species as compared to aircraft observations [see Lamarque et al., 2008]. In order to simulate the formation of secondary organic aerosols (SOA) from monoterpenes, several additional chemical equations describing the oxidation path of monoterpenes, as done in MOZART [Lack et al., 2004] were included; other hydrocarbons leading to SOA forma- 
tion were already included in the Houweling et al. [1998] chemical mechanism. The CAM-Chem model has 81 transported species and 152 chemical reactions. CAMChem model does not contain aromatic hydrocarbons.

[13] The anthropogenic emissions are from POET inventory (available at http://www.aero.jussieu.fr/projet/ACCENT/ POET.php), except over Asia, where Regional Emission inventory in ASia (REAS) data is used. The biomass burning emissions are according to the Global Fire Emissions version 2 (GFEDv2) database. The emissions used represent those of year 2004. Tropospheric ozone concentration simulated by the CAM-Chem model were compared to ozonesonde climatology by Lamarque et al. [2008]. Lamarque et al. [2008] show that CAM-Chem is able to simulate the observed seasonality, with a general tendency toward a negative bias in the upper troposphere.

\subsection{The ECHAM5-MOZ Model}

[14] The ECHAM5-MOZ is a tropospheric chemistry climate model containing the tropospheric chemistry of MOZART2.4 [Horowitz et al., 2003], which is fully embedded in the general circulation model ECHAM5 [Roeckner et al., 2003]. The setup used in this paper has an horizontal resolution of $2.8^{\circ}$ latitude by $2.8^{\circ}$ longitude, and 31 hybrid sigma pressure vertical levels, from the surface to $10 \mathrm{hPa}$. The model temperature, vorticity, divergence, surface pressure and sea surface temperature was constrained toward the operational forecast data of the European Centre for Medium Range Weather Forecast (ECMWF) through the nudging technique [Jeuken et al., 1996].

[15] The tropospheric chemistry of MOZART 2.4 include reactions involving $\mathrm{NO}_{x}-\mathrm{HO}_{x}-\mathrm{O}_{x}-\mathrm{CO}-\mathrm{CH}_{4}$ and other hydrocarbons, including oxygenated hydrocarbons. The heterogenous reaction of $\mathrm{N}_{2} \mathrm{O}_{5}$ on sulphate aerosols are also included. The model includes both dry and wet deposition, which are formulated according to Ganzeveld [2001] and Stier et al. [2005], respectively. The upper boundary concentrations for ozone, $\mathrm{NO}_{x}, \mathrm{HNO}_{3}$, and $\mathrm{N}_{2} \mathrm{O}_{5}$ were fixed at the top levels higher than $30 \mathrm{hPa}$ in the model, and are prescribed based on climatological zonal and monthly mean values described by Horowitz et al. [2003]. The concentrations above the model tropopause are relaxed toward these climatological values with a constant relaxation time of 10 days. The photolysis rates are derived from tabulated values from the Tropospheric Ultraviolet and Visible radiation model [Madronich and Flocke, 1999], with an update for $\mathrm{O}\left({ }^{1} \mathrm{D}\right)$ from the photolysis of ozone as described by Horowitz et al. [2003]. The full chemical scheme in the ECHAM5-MOZ model contains 168 chemical reactions and 63 transported species.

[16] The simulation employs the anthropogenic and biomass burning emissions of year 2000, which are created during the Reanalysis of the Tropospheric Chemical Composition over the past 40 years (RETRO) project [Schultz et al., 2007]. Lightning $\mathrm{NO}_{X}$ and vegetation emissions are calculated interactively within the model based on the parameterization of Grewe et al. [2001] and the Model of Emissions of Gases and Aerosols from Nature (MEGAN) [Guenther et al. 2006], respectively. The ECHAM5-MOZ model has been extensively evaluated against sondes and aircraft data [Aghedo, 2007; Aghedo et al., 2007]. ECHAM5-MOZ is able to simulate the observed seasonal variation of tropospheric ozone, with positive bias of not more than $30 \mathrm{ppbv}$ in comparison with sondes and aircraft data in the free troposphere [Aghedo, 2007; Aghedo et al., 2007]. The ECHAM5-MOZ model is also shown to have a positive bias of about $20 \%$ in the global tropospheric ozone production and loss compared to the multimodel mean [Stevenson et al., 2006].

\subsection{The GISS-PUCCINI Model}

[17] The model GISS-PUCCINI is the NASA Goddard Institute for Space Studies (GISS) atmospheric composition and climate model. It consists of the model for Physical Understanding of Composition-Climate Interactions and Impacts (PUCCINI) [Shindell et al., 2006b], which is fully embedded in the GISS modelE climate model [Schmidt et al., 2006]. The model contains both tropospheric and stratospheric chemistry. The model was run at $2^{\circ}$ latitude by $2.5^{\circ}$ longitude Cartesian horizontal resolution, with increased effective resolution for tracers by carrying higher-order moments at each grid box. This configuration has 40 vertical hybrid sigma layers from the surface to $0.1 \mathrm{hPa}(80 \mathrm{~km})$. Simulations were performed using observed sea surface temperatures [Rayner et al., 2003] and linear relaxation of winds toward NCEP/NCAR reanalysis [Kalnay et al., 1996].

[18] Tropospheric chemistry includes basic $\mathrm{NO}_{x}-\mathrm{HO}_{x}-$ $\mathrm{Ox}-\mathrm{CO}-\mathrm{CH}_{4}$ chemistry as well as PAN, isoprene, alkyl nitrates, aldehydes, alkenes, paraffins, and other hydrocarbons. The lumped hydrocarbon family scheme was derived from the Carbon Bond Mechanism-4 [Gery et al., 1989] and from the more extensive Regional Atmospheric Chemistry Model, following [Houweling et al., 1998]. The stratospheric chemistry includes chlorine- and brominecontaining compounds, and $\mathrm{CFC}$ and $\mathrm{N}_{2} \mathrm{O}$ source gases. The main additions to the previous versions are the addition of acetone to the hydrocarbons following [Houweling et al., 1998], polar stratospheric cloud formation now depends upon the abundance of nitric acid, water vapor and temperature [Hanson and Mauersberger, 1988], and the addition of a reaction pathway for $\mathrm{HO}_{2}+\mathrm{NO}$ to yield $\mathrm{HNO}_{3}$ [Butkovskaya et al., 2007]. Photolysis rates are calculated using the Fast-J2 scheme [Bian and Prather, 2002], whereas other chemical reaction rate coefficients are from Sander et al. [2000]. Tracer transport uses a nondiffusive quadratic upstream scheme [Prather, 1986]. The full scheme includes 156 chemical reactions among 50 species.

[19] Year 2000 emissions were used from the data set assembled for the IPCC fifth assessment report simulations [Lamarque et al., 2010]. The GISS-PUCCINI model has been compared with observations [e.g., Dentener et al., 2006; Shindell et al., 2006a, 2006b] and other models [Stevenson et al., 2006]. It performs well at simulating ozone concentrations. However, it has a general tendency to be negatively biased to measurements and has the strongest biases in the upper troposphere.

\section{Tropospheric Emission Spectrometer}

\subsection{TES Ozone Data}

[20] The Tropospheric Emission Spectrometer (TES) provides the vertical profiles of tropospheric ozone on a global-scale. TES is an infrared, high-resolution, Fourier transform spectrometer covering the spectral range from 650 


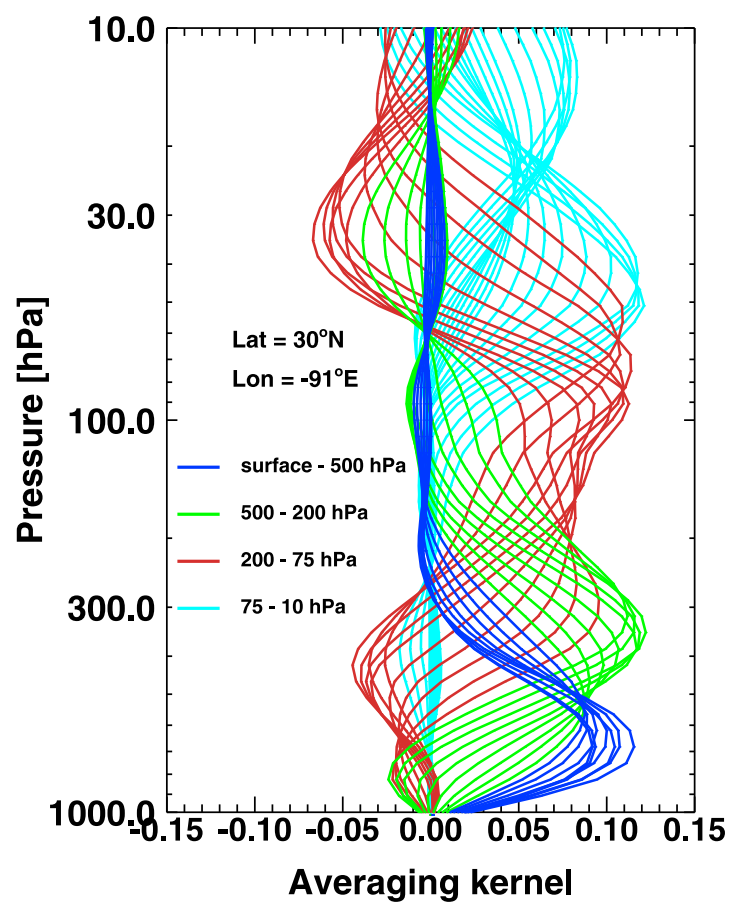

Figure 1. TES averaging kernels corresponding to the pressure levels indicated in the legend at latitude $30^{\circ} \mathrm{N}$ and longitude $91^{\circ} \mathrm{W}$.

to $3050 \mathrm{~cm}^{-1}(15.4-3.3 \mu \mathrm{m})$ with an apodized spectral resolution of $0.1 \mathrm{~cm}^{-1}$, and an averaged nadir footprint of about $5 \mathrm{~km}$ by $8 \mathrm{~km}$ [Beer et al., 2001]. TES operates in a polar Sun-synchronous orbit with a repeat cycle of 16 days. The spectral radiances measured by TES are used to retrieve the atmospheric profiles through a nonlinear optimization algorithm that minimizes the difference between observed radiances and those calculated with an RTM, subject to the condition that the solution is consistent with an a priori description of the atmosphere [Rodgers, 2000; Bowman et al., 2002, 2006]. The retrieved ozone profile $\hat{\mathbf{x}}$ is an estimate of the true atmospheric profile $\mathbf{x}$ and it can be expressed as

$$
\hat{\mathbf{x}}=\mathbf{x}_{a}+\mathbf{A}\left(\mathbf{x}-\mathbf{x}_{a}\right)+\epsilon
$$

where $\mathbf{x}_{a}$ is the a priori profile, $\mathbf{A}$ is the averaging kernel matrix, $\epsilon$ is the observational error, whose covariance account for the random and systematic errors and errors associated with joint retrieval of dependent states [Worden et al., 2004]. The profiles: $\mathbf{x}_{a}, \mathbf{x}$ and $\hat{\mathbf{x}}$ are expressed as natural logarithm of the volume mixing ratio. TES ozone profiles have 67 vertical levels with varying layer thickness, which are a subset of the pressure levels of the TES radiative transfer forward model [Clough et al., 2002].

[21] The analysis presented in this paper employs TES version 3 data. We use TES ozone data collected in August 2006 from the standard global survey mode (with 16 day repeat cycle, which is the number of days before TES samples about the same latitude and longitude) and a less frequent special observations mode (using the step and stare with nadir viewing of approximately $1 / 6$ of an orbit, zooming in on a particular region). The global survey mode includes both daytime and nighttime ozone measurements. We compared model monthly mean sampled across TES profiles and averaged to the model's original resolution with the individual model original monthly mean. We found that despite the coarse diurnal sampling by TES, the monthly mean calculated from the sampled profiles is able to capture the synoptic-scale variability of ozone in the month of August. The bias associated with sampling is less than $10 \%$ within the free troposphere below $350 \mathrm{hPa}$, and could be up to $20 \%$ in the Southern Hemisphere midlatitude upper troposphere-lower stratosphere (UTLS). The detail analysis of errors associated with sampling will be the focus of another paper. We use all TES data collected in the global surveys and special observations of August 2006 with the exception of data with bad quality flags (i.e., master retrieval quality $\neq$ 1.0 (for additional details, see Osterman et al. [2009]). TES ozone data have been evaluated by comparison to ozonesondes [e.g., Bowman et al., 2009; Nassar et al., 2008; Worden et al., 2007], aircraft data [e.g., Richards et al., 2008], and ozone measured by other satellite instruments, for example, OMI and MLS [e.g., Osterman et al., 2008]. These studies show that TES ozone has a positive bias, and within the troposphere, the bias varies between 3-10 ppbv [Nassar et al., 2008]. We account for this bias with the same approach used by Worden et al. [2008] by reducing TES ozone abundance by $15 \%$ everywhere.

\subsection{Applying TES Operators to Model Data}

[22] The procedure for comparing model with TES was originally developed by Jones et al. [2003]. This procedure has been extensively used in the comparison of TES ozone against in situ measurements, such as sondes and aircraft [e.g., see Worden et al., 2007; Richards et al., 2008], and assimilation of TES data [Parrington et al., 2008, 2009; Jones et al., 2009]. The main objective is to account for TES limited vertical resolution. This involves applying TES a priori profile and averaging kernels (which are together referred to as TES operators) to models ozone concentration. The averaging kernels (see example in Figure 1) and a priori profile are included in every TES HDF-EOS metadata product. The TES a priori ozone profiles are derived from the climatology based on the MOZART model, which was regridded to 10 degree latitude by 30 degrees longitude.

[23] Due to the difference in spatial and temporal resolution between TES and the models, we use TES spatiotemporal information to extract model ozone profiles whose grid overlaps with TES, before we apply TES operators to the extracted model profiles. The temporal resolution for all models is 3 hourly. These extracted ozone profiles from models were then interpolated from the individual model pressure levels to TES pressure levels, which consists of 67 levels from the surface to $0.1 \mathrm{hPa}$. The linear interpolation was performed on the natural logarithm of the models' ozone volume mixing ratios. The models containing only tropospheric chemistry and lower top-of-model pressure than TES top-of-atmosphere exhibit anomalous ozone concentrations in the upper stratosphere, especially at pressure levels above $10 \mathrm{hPa}$ because the extrapolation linearly stretches the values at the respective model top (e.g., $10 \mathrm{hPa}$ in the ECHAM5- 

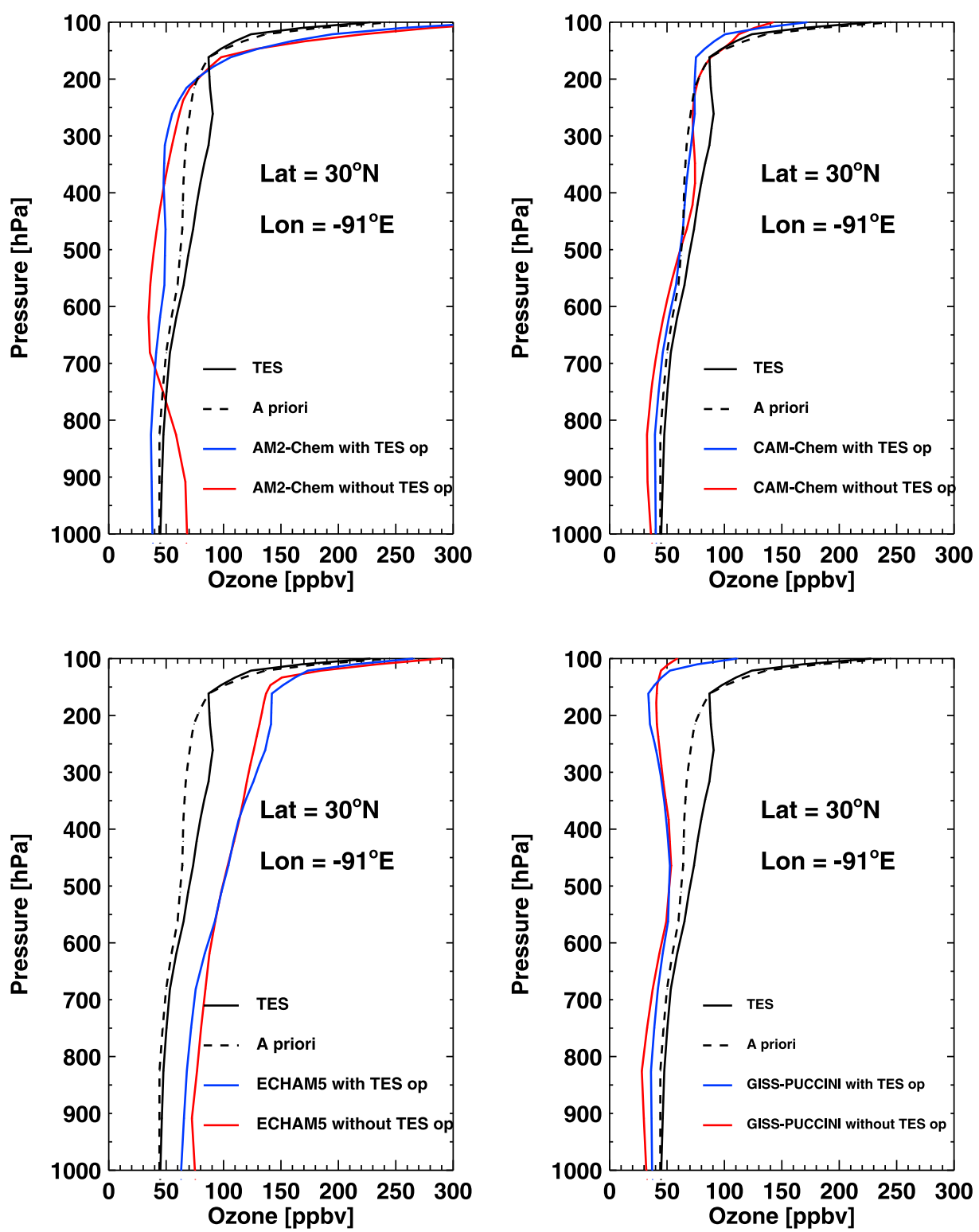

Figure 2. The vertical profile example of TES ozone (black), a priori models (dashed black line), and ozone before (solid red line) and after (solid blue line) the application of TES operators at latitude $30^{\circ} \mathrm{N}$ and longitude $91^{\circ} \mathrm{W}$. The rows of the averaging kernel matrix for this location are shown in Figure 1.

MOZ model, $4 \mathrm{hPa}$ in CAM-Chem) to $0.1 \mathrm{hPa}$. In these models (i.e., the AM2-Chem, ECHAM5-MOZ and CAM-Chem models), we replace the unavailable stratospheric ozone concentrations with TES a priori above $30 \mathrm{hPa}$. TES operators were then applied to these modified and interpolated vertical profiles from each of the models. Subsequently in this paper, model ozone refers to model profiles sampled at TES locations, and corrected for TES sensitivity as explained in this section.

[24] The logarithm of the ozone mixing ratios from the model $\mathbf{x}^{\mathbf{m}}$ (i.e., extracted and vertically interpolated model ozone) replaces the true atmospheric profile in equation (1):

$$
\hat{\mathbf{x}}^{m}=\mathbf{x}_{a}+\mathbf{A}\left(\mathbf{x}^{m}-\mathbf{x}_{a}\right)
$$

The comparison between the "retrieved" model ozone $\hat{\mathbf{x}}^{m}$ and TES $\hat{\mathbf{x}}$ is not biased by TES a priori, and account for the vertical smoothing of the retrieval. Note that $x$ in equation (2) is the natural logarithm of ozone volume mixing ratio as shown in equation (3).

[25] Figure 2 shows an example of ozone vertical profiles at latitude $30^{\circ} \mathrm{N}$ and longitude $91^{\circ} \mathrm{W}$. Figure 2 shows TES ozone (black solid lines), the a priori (black dashed lines), and the models ozone profiles: before TES operators (red solid lines), and after TES operators were applied (blue lines). Figure 2 shows that TES retrieved profile is significantly different from the a priori profile below $100 \mathrm{hPa}$. This indicates that TES has sensitivity over most of the troposphere, as shown by the averaging kernel for this location (see Figure 1). It is important to bear in mind that the 
averaging kernel varies with location, and it is vital to understanding the regions of the vertical profile where TES is sensitive. When the averaging kernel goes to zero, TES measurements will revert to the a priori values, as shown in equation (1).

\subsection{TES IRF Kernels}

[26] We decompose the variability of the OLR observed by TES to the product of sensitivity of the OLR to variations in ozone, and to variation of ozone concentration itself. We termed the sensitivity of OLR to variation in ozone the instantaneous radiative forcing kernels (IRFK). We calculate these IRFK at the top of the atmosphere due to changes in the ozone concentration at any level, and derive a three-dimensional satellite-based products that could be used to evaluate tropospheric ozone OLR forcing in global chemistry climate models. The detailed description of TES IRFK calculations is presented by Worden et al. (submitted manuscript, 2010). In this paper, we focus on the comparison of IRF from TES and the global chemistry climate models that participated in the project for the purpose of characterizing an observational constraint error in the predicted climate forcing of tropospheric ozone by models.

[27] Note that these kernels provide a more detailed description of OLR sensitivity than those presented by Worden et al. [2008], which were derived from empirical calculations of OLR reduction due to upper tropospheric ozone and were only possible for ocean surface and clearsky conditions.

[28] Converting TES (and model) ozone $\hat{\mathbf{x}}$ in equation (1) (and equation (2)) from logarithm of volume mixing ratio to $q$ in units of ppbv gives

$$
q_{i}(z)=10^{9} \exp \left(\hat{x}_{i}(z)\right)
$$

where $i$ denotes the time-dependent horizontal location (i.e., particular latitude, longitude at a given time), and $z$ is the pressure level, which extends from the surface up to $0.1 \mathrm{hPa}$.

[29] At the top-of-the-atmosphere (TOA), changes in radiance $L$ due to changes in ozone volume mixing ratio $q$ is given in units of $\mathrm{W} \mathrm{m}^{-2} \mu \mathrm{m}^{-1} \mathrm{str}^{-1} \mathrm{ppbv}^{-1}$ by

$$
\frac{\partial L_{i}^{T O A}\left(z, \nu, \theta, \phi, q_{i}(z)\right)}{\partial q_{i}(z)}=\frac{1}{q_{i}(z)} \frac{\partial L_{i}^{T O A}\left(z, \nu, \theta, \phi, q_{i}(z)\right)}{\partial\left(\ln q_{i}(z)\right)}
$$

where $\nu$ represents the spectral frequency, $\theta$ is the satellite viewing zenith angle, and $\phi$ is the relative azimuth angle, which defines the position of the satellite relative to the solar plane. The TOA flux, $F_{i}^{T O A}$ is given by

$F_{i}^{T O A}\left(z, \nu, q_{i}(z)\right)=\int_{0}^{2 \pi} \int_{0}^{\frac{\pi}{2}} L_{i}^{T O A}\left(z, \nu, \theta, \phi, q_{i}(z)\right) \cos \theta \sin \theta \mathrm{d} \theta \mathrm{d} \phi$

where the angular integrals account for directional dependency of radiance observed by a satellite instrument, i.e., anisotropy [e.g., see Loeb et al., 2003]. The details of the anisotropy calculation for TES are given by Worden et al. (submitted manuscript, 2010). The finite difference approximation of TOA flux with respect to ozone volume mixing ratio, $q$ is given by

$$
F(z, \nu, q+\mathrm{d} q)-F(z, \nu, q) \approx \frac{1}{q} \frac{\partial F(z, \nu, q)}{\partial \ln q} \mathrm{~d} q
$$

[30] Integrating the derivative of the flux with respect to ozone volume ratio over the entire ozone spectral band yields the instantaneous radiative forcing kernel, $H$ in units of $\mathrm{Wm}^{-2} \mathrm{ppbv}^{-1}$ :

$$
H_{i}\left(z, q_{i}(z)\right)=\frac{1}{q_{i}(z)} \int_{\nu_{1}}^{\nu_{2}} \frac{\partial F_{i}^{T O A}\left(z, \nu, q_{i}(z)\right)}{\partial\left(\ln q_{i}(z)\right)} \mathrm{d} \nu
$$

and $\nu_{1}=9.26 \mu \mathrm{m}$ through $\nu_{2}=10.2 \mu \mathrm{m}$ spans the $9.6 \mu \mathrm{m}$ ozone band. We accounted for the systematic bias in TES ozone abundance in the calculation of the instantaneous radiative forcing kernels. This correction resulted in $18 \%$ increase in the IRFK with respect to the values not corrected. This is further described by Worden et al. [2008] and Worden et al. (submitted manuscript, 2010).

[31] The direct observations of infrared radiance at high spectral resolution by the TES instrument provide a satellite-based estimate of the OLR sensitivity to ozone. Moreover, this approach provides the first three-dimensional characterization of OLR forcing by ozone from space, with immediate applications in chemistry-climate model evaluation. TES profiles of ozone IRFK are derived for both clear and cloudy sky conditions.

[32] Figure 3 shows the zonal mean of the instantaneous radiative forcing kernels for both clear sky and total sky in August 2006. The clear-sky IRFK are higher than the totalsky IRFK, showing that clouds reduce the overall IRFK values. Figure 3 also shows that clouds shift the peak sensitivity from $450 \mathrm{hPa}$ to $400 \mathrm{hPa}$. Soden et al. [2008] also found that clouds reduce the overall water vapor kernel values and shift the peak sensitivity to the upper troposphere and to the subtropical regions where there are fewer highlevel clouds. Clouds have a strong effect on total OLR by reducing the sensitivity of the OLR to absorption and emission in the lower troposphere for all gases, including ozone [Lelieveld and Crutzen, 1990]. This feedback is highly nonlinear and depends on the location of the clouds [Zhu et al., 2001]. Figure 3 shows that outgoing longwave radiation is mostly sensitive to variations in the tropical and midlatitudes ozone, and also to changes in middle tropospheric ozone. This midtropospheric sensitivity is a consequence of change in volume mixing ratio concentrations having a larger effect on total column in the middle troposphere than at the upper troposphere. The largest IRF kernel values, those greater than $0.5 \mathrm{~mW} / \mathrm{m}^{2} / \mathrm{ppbv}$, were located in between $200 \mathrm{hPa}$ and $650 \mathrm{hPa}$. Outside of this altitude range, the kernels decrease almost linearly (see Figure 3).

\section{Models Tropospheric Ozone Evaluation}

\subsection{Models Evaluation With Respect to TES Ozone}

[33] Figure 4 shows the zonal mean distribution of tropospheric ozone concentrations measured by TES and the zonal mean bias of each of the models with respect to TES in August 2006. The multimodel mean ozone bias shows the 

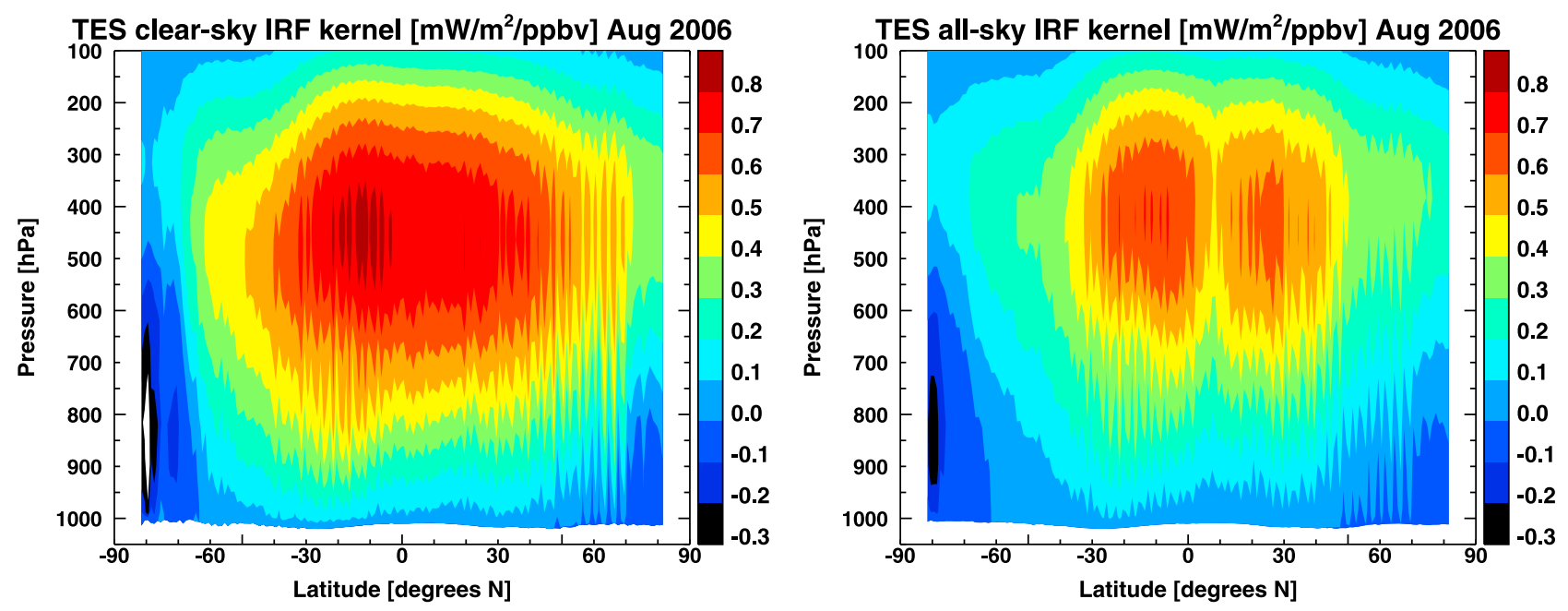

Figure 3. The zonal mean distribution of the (top) clear-sky and (bottom) total-sky instantaneous radiative forcing kernels (IRFK, in $\mathrm{mW} / \mathrm{m}^{2} / \mathrm{ppbv}$ ) in August 2006.

average ozone bias in the four global chemistry climate models. The ozone magnitude simulated by each of the models reveals various discrepancies.

[34] In comparison to TES ozone, the AM2-Chem model shows a negative bias of about -20 ppbv over the northern tropical and midlatitudes within the entire troposphere. The model also shows negative bias of up to $-55 \mathrm{ppbv}$ in the northern polar upper troposphere. The AM2-Chem model has positive bias of about $35 \mathrm{ppbv}$ in the upper troposphere Southern Hemisphere (Figure 4b) in comparison with TES. The CAM-Chem model shows the least bias of all the models, of about $10 \mathrm{ppbv}$ in the entire free troposphere. Close to the tropopause, the CAM-Chem model shows predominantly negative bias of between 20 and $30 \mathrm{ppbv}$ (Figure 4c).

[35] The ECHAM5-MOZ model overestimates ozone concentrations by up to $40 \mathrm{ppbv}$ in the lower to middle troposphere, especially at the tropical and northern latitudes (Figure 4d). The ECHAM5-MOZ model bias can increase to more than $60 \mathrm{ppbv}$ in the upper troposphere. The GISSPUCCINI model underestimates ozone concentrations almost everywhere, except at the southern latitudes in the lower to middle troposphere, where the positive bias are generally low (Figure 4e). The GISS-PUCCINI model bias reaches $-20 \mathrm{ppbv}$ in the lower to middle troposphere, and $-60 \mathrm{ppbv}$ in the upper troposphere.

[36] The multimodel mean zonal mean ozone (Figure 4f) shows the lowest absolute bias in the Southern Hemisphere throughout the troposphere, due in part to the cancelation of the biases from a model by another model. The multimodel zonal mean ozone has negative biases in the Northern Hemisphere, because ECHAM5-MOZ positive biases do not fully compensate for the negative biases of the three remaining models.

[37] In Figure 5, we show the spatial correlation of models and ozone concentrations at all pressure levels in the troposphere. The AM2-Chem model exhibits the lowest correlation among all the models throughout the troposphere. This low spatial correlation of AM2-Chem model is due to positive bias in the Southern Hemisphere and negative bias in the Northern Hemisphere, which lead to inconsistent spatial distributions in comparison to TES. The ECHAM5MOZ model has the highest spatial correlation of about 0.7 below $500 \mathrm{hPa}$. Above $450 \mathrm{hPa}$, GISS-PUCCINI spatial pattern is the most similar to those of TES, and it shows a spatial correlation ranging from 0.66 to 0.94 with increasing vertical height. The relatively low spatial correlation exhibited in the AM2-Chem model around $550-250 \mathrm{hPa}$ was improved in the AM2-Chem-assim (red dashed lines), due to the improvement in the Northern Hemisphere at these pressure levels. Equally, the multimodel mean (black dashed lines) has correlation higher or equal to 0.7 from 650 to $350 \mathrm{hPa}$, and also has the highest correlation of all models, except ECHAM5-MOZ in the entire troposphere.

\subsection{Sources of Model Differences}

[38] There are several sources of differences among the models. These include differences in spatial and vertical resolutions, emissions (since every model uses different emissions), different levels of details in chemistry (for example all models except GISS-PUCCINI use varied versions of MOZART tropospheric chemistry, v2 in AM2Chem, v2.4 in ECHAM5-MOZ and v3 in CAM-Chem. In addition, CAM-Chem and GISS-PUCCINI models have stratospheric chemistry, while the other two are mainly tropospheric chemistry climate models), different number of chemical reactions incorporated into the models, and meteorology (AM2-Chem and GISS-PUCCINI were constrained by NCEP reanalysis, ECHAM5-MOZ was nudged to the ECMWF operational forecast data, and CAM-Chem performs no nudging). It is therefore very difficult to characterize which of these differences makes the largest contribution to the biases we see in Figure 4. Since the aim of this paper is not to characterize model differences (as reflected in our model setup), but how those differences will influence the instantaneous radiative forcing calculations, we therefore provide very generalized explanations.

[39] Lightning $\mathrm{NO}_{x}$ emissions have been shown to drive about $20 \%$ of total ozone column variability [Martin et al., 
(a) $\mathrm{TES} \mathrm{O}_{3}$ [ppbv] zonal-mean Aug 2006
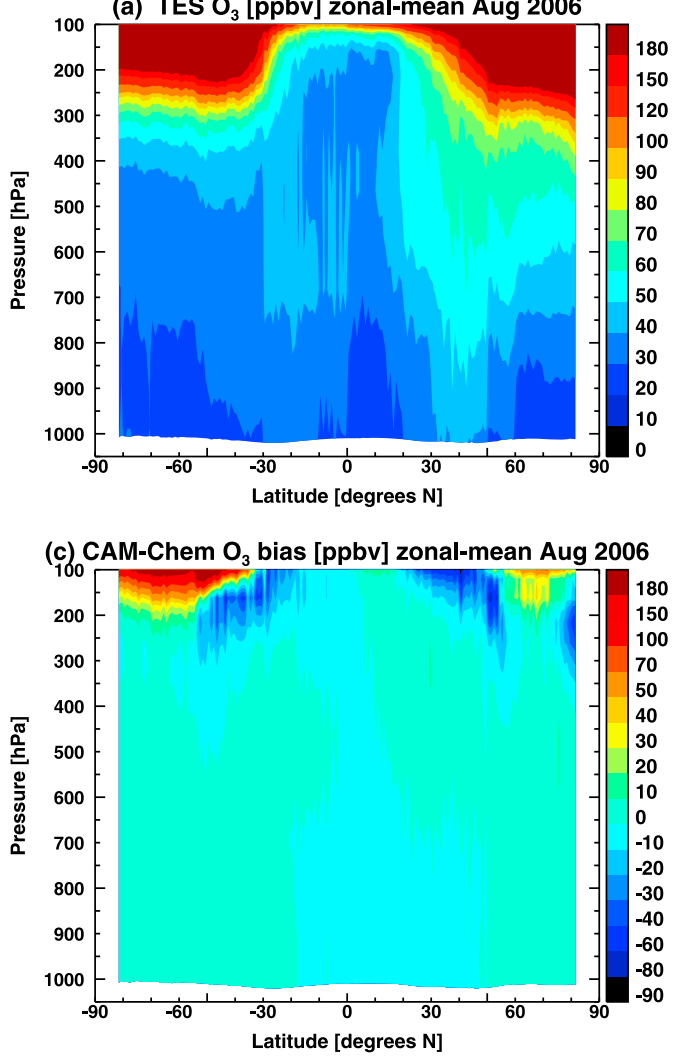

(e) GISS-PUCCINI O ${ }_{3}$ bias [ppbv] zonal-mean Aug 2006

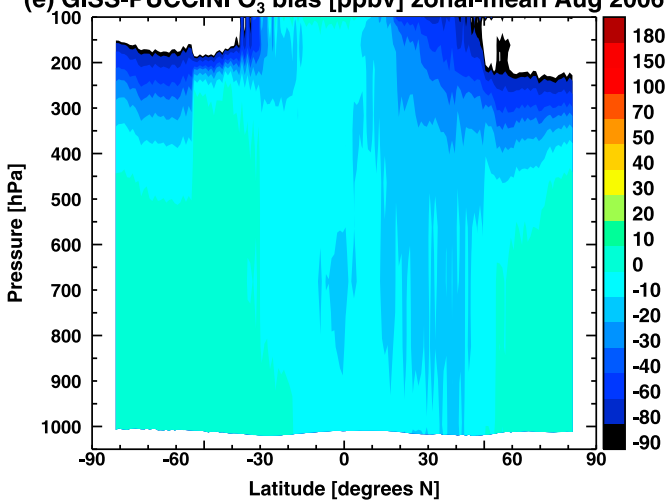

(g) AM2-Chem-assim $\mathrm{O}_{3}$ bias [ppbv] zonal-mean Aug 2006

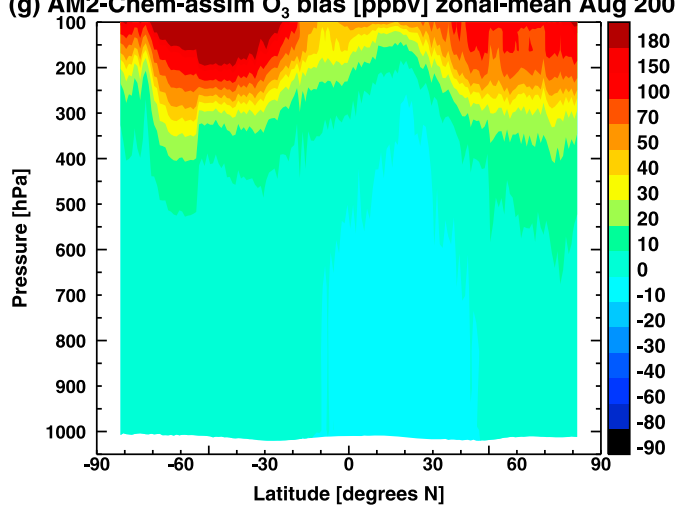

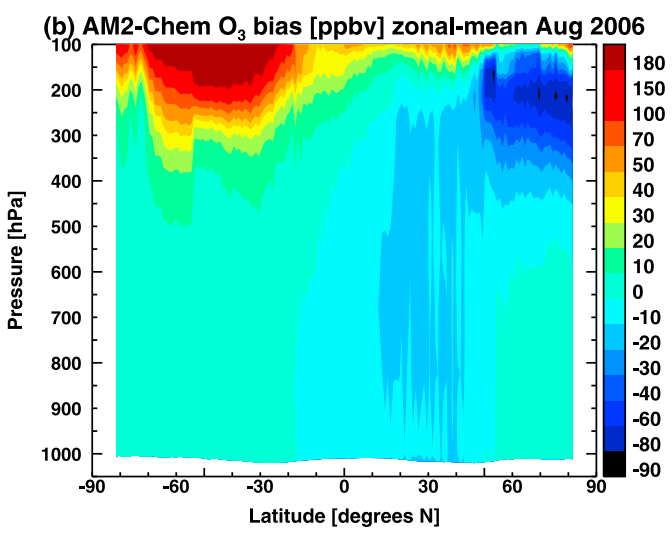

(d) ECHAM5-MOZ O 3 bias [ppbv] zonal-mean Aug 2006
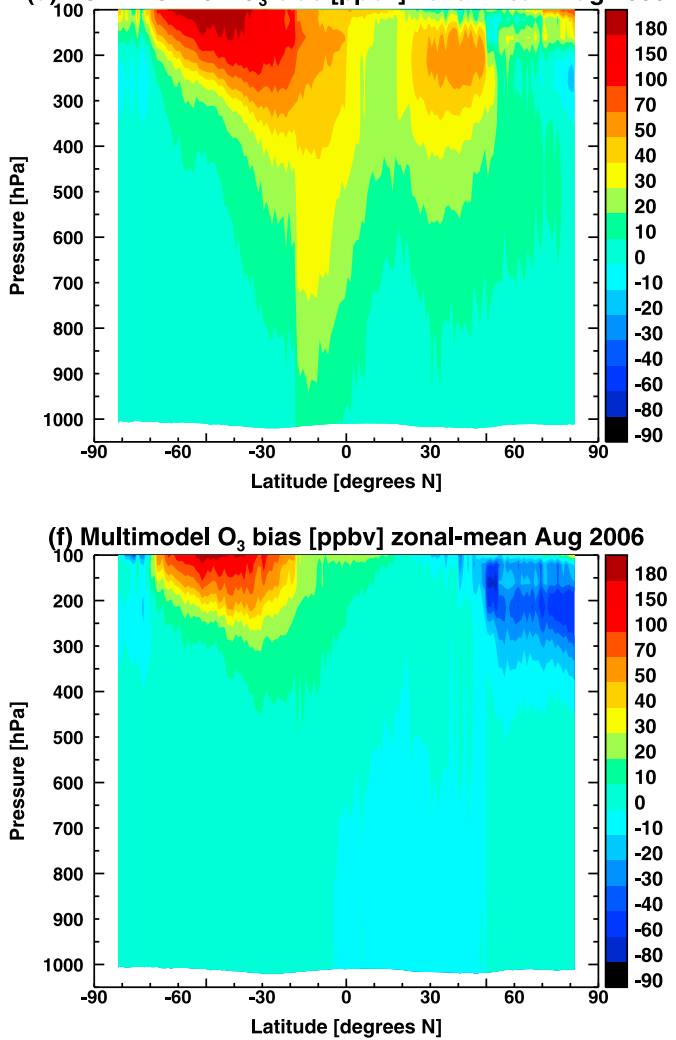

Figure 4. (a) The zonal mean distribution of ozone concentration measured by TES and the zonal mean ozone bias in the (b) AM2-Chem, (c) CAM-Chem, (d) ECHAM5-MOZ, and (e) GISS-PUCCINI models in August 2006. The zonal mean ozone bias of the (f) multimodel mean and (g) AM2-Chem-assim models are also shown. The biases are calculated as models minus TES. 


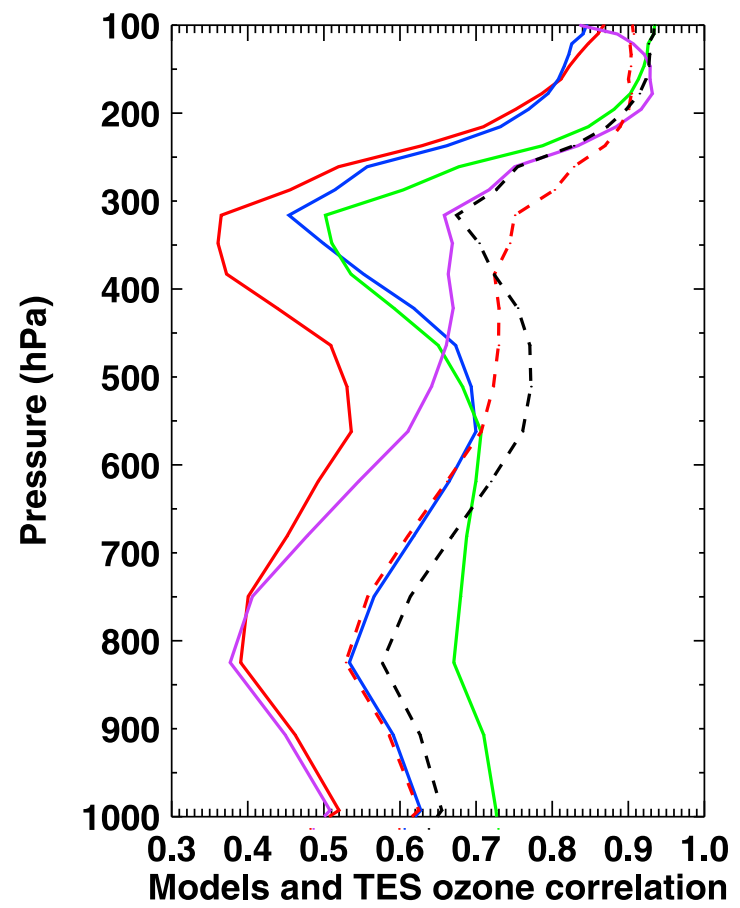

Figure 5. The spatial pattern correlation, $r$, of models with TES ozone at every pressure level for AM2-Chem (solid red line), CAM-Chem (solid blue line), ECHAM5-MOZ (solid green line), GISS-PUCCINI (solid magenta line), multimodel mean (dashed blackline), and AM2-Chem-assim (dashed red line). The correlation uses model and TES ozone data of August 2006. Note that we did not correct model ozone bias before we calculated the correlations.

2000] and are mainly responsible for sustaining ozone production in the middle to upper troposphere [e.g., Hauglustaine et al., 2001]. The total amount of lightning $\mathrm{NO}_{x}$ emissions calculated online within each of our models varies. Their magnitude range from $0.27 \mathrm{Tg}(\mathrm{N}) /$ month in AM2-Chem to $0.99 \mathrm{Tg}(\mathrm{N}) /$ month in GISS-PUCCINI models. The CAM-Chem and ECHAM5-MOZ models falls in between this range with a total lightning $\mathrm{NO}_{x}$ emissions of 0.37 and $0.57 \operatorname{Tg}(\mathrm{N}) /$ month, respectively. This may explain some of the differences in ozone concentration exhibited by the models in the middle and upper troposphere (as shown in Figure 4).

[40] The meteorology of the AM2-Chem and GISSPUCCINI models were nudged to NCEP data. Both models show similar negative bias in comparison to TES data at the Northern Hemisphere. In order to test if NCEP reanalysis is responsible for the negative bias, we performed additional sensitivity analysis with the GISS-PUCCINI model by turning off the "nudging" procedure. This "free run" sensitivity shows that the use of NCEP data caused a slow down of stratosphere-troposphere exchange, causing up to $60 \%$ and $80 \%$ reduction in the ozone concentration around the tropopause in the Northern and Southern hemispheres, respectively.

[41] The ECHAM5-MOZ model was nudged to the ECMWF forecast data. In a model simulation that investigates the influence of prescribed meteorology fields on the transport of tracers, Aghedo et al. [2008] shows that the use of ECMWF forecast data causes up to $70 \%$ increase in the downward transport from the stratosphere, and about a factor of 2.5 increase in surface tracers that get transported to the stratosphere. This ECMWF data artifact was also found by Van Noije et al. [2004] in a different model simulation that investigates the stratosphere-troposphere exchange sensitivity to meteorological data. In a separate sensitivity analysis, we found that this intense Brewer-Dobson circulation due to the ECMWF data could cause between 30 and $40 \%$ additional ozone in the midlatitudes upper troposphere, and up to $30 \%$ more ozone throughout the tropical troposphere, relative to free run simulation. The ECHAM5-MOZ model has also been shown to have a relatively lower surface deposition in comparison to similar chemistry climate models (see MOZECH and MOZECH2 model performance in the work by Stevenson et al. [2006]). The combination of this low deposition and high mixing may be the largest driver of ECHAM5-MOZ high positive bias in comparison to TES measurement.

[42] The influence of prescribed meteorology on the simulation of ozone stated above may not represent model performance in general, since this study is only for one month. The impact of nudging will be studied over longer times in a subsequent paper.

\section{Tropospheric Ozone Instantaneous Radiative Forcing}

\subsection{TES IRF and Models' IRF Biases Calculation}

[43] The discrete form of the ozone profiles $q_{i}(z)$ in equation (3) and the IRFK $H_{i}(z)$ given in equation (6) across a discrete altitude dimension $z_{k}$, where $k=1, \ldots, N$ and $N=67$ is the highest level of TES and model profiles (i.e., $0.1 \mathrm{hPa}$ ) is given by $H_{i}\left(z_{k}\right)$ and $q_{i}\left(z_{k}\right)$, respectively. Then, the total-sky three-dimensional instantaneous radiative forcing, IRF is given by

$$
\operatorname{IRF}_{i}^{T E S}\left(z_{k}\right)=H_{i}\left(z_{k}\right)\left\{q_{i}^{T E S}\left(z_{k}\right)\right\}
$$

According to equation (5), equation (7) can be interpreted as the instantaneous forcing of a $100 \%$ change in ozone. The respective instantaneous radiative forcing discrepancies $\triangle \mathrm{IRF}$ in each of the models $m$ is equally given by

$$
\Delta \operatorname{IRF}_{i}^{m}\left(z_{k}\right)=H_{i}\left(z_{k}\right)\left\{q_{i}^{m}\left(z_{k}\right)-q_{i}^{T E S}\left(z_{k}\right)\right\}
$$

The instantaneous radiative forcing discrepancies calculated according to equation (8) represent the radiative impact of differences in ozone distribution calculated by models with respect to TES. Applying TES observed OLR sensitivity (i.e., the IRF kernels) to the biases in models' ozone distribution provide an observationally based platform for standardization across multimodels.

[44] The integration of equations (7) and (8) over the pressure levels within the troposphere gives the total tropospheric IRF, which is given by

$$
\operatorname{TIRF}_{i}^{T E S}=\sum_{k=1}^{\mathrm{K}} \operatorname{IRF}_{i}^{T E S}\left(z_{k}\right)
$$




$$
\Delta \operatorname{TIRF}_{i}^{m}=\sum_{k=1}^{\mathrm{K}} \Delta \operatorname{IRF}_{i}^{m}\left(z_{k}\right)
$$

where $\mathrm{K}$ represents the thermal tropopause following the definition of WMO calculated from TES.

[45] Zonal mean IRF profiles, ZIRF are also calculated from equations (7) and (8) as

$$
\begin{aligned}
\operatorname{ZIRF}_{i \in I}^{T E S}\left(z_{k}\right) & =\frac{\sum_{i \in J} \operatorname{IRF}_{i}^{T E S}\left(z_{k}\right)}{\sum_{i \in J} i} \\
\Delta \operatorname{ZIRF}_{i \in I}^{m}\left(z_{k}\right) & =\frac{\sum_{i \in J} \Delta \operatorname{IRF}_{i}^{m}\left(z_{k}\right)}{\sum_{i \in J} i}
\end{aligned}
$$

where $I$ and $J$ denote the latitude and longitude dimensions, respectively. The vertical profile of the global average of IRF biases in models, $\triangle$ VIRF is calculated as

$$
\Delta \operatorname{VIRF}^{m}\left(z_{k}\right)=\frac{\sum_{i \in(I \cup J)} \Delta \operatorname{IRF}_{i}^{m}\left(z_{k}\right) W_{i}}{\sum_{i \in(I \cup J)} W_{i}}
$$

where $W$ is the surface area of the earth bounding $i$ and $j$ within a box.

\subsection{TES Instantaneous Radiative Forcing}

[46] TES tropospheric IRF defined in equation (9) is shown in Figure 6a. Figure 6a shows that the instantaneous OLR forcings are strongest in tropical and midlatitudes from $30^{\circ} \mathrm{S}$ to $60^{\circ} \mathrm{N}$ latitudinal band. TES shows slightly higher instantaneous radiative forcing values over the Northern Hemisphere than the Southern Hemisphere, due to higher summer temperature and other conditions that favor higher ozone concentrations, such as slightly higher stratospheric intrusion at the Northern Hemisphere (see Figure 7a).

[47] Comparing the zonal mean IRF (as defined in equation (11)) shown in Figure $7 \mathrm{a}$ and the total-sky IRF kernel in Figure 3 reveal that although OLR is mostly sensitive to the tropical middle-tropospheric ozone, largest values of IRF are located at the polar UTLS region. This is due to the large concentration of ozone in the polar UTLS, which compensates for low sensitivity to OLR. For example, the total-sky zonal mean IRF kernels recorded throughout the polar UTLS region is only up to $0.3 \mathrm{~mW} / \mathrm{m}^{2}$ / ppbv, and we calculate zonal mean instantaneous radiative forcing of up to $70 \mathrm{~mW} / \mathrm{m}^{2}$ there, whereas within the tropical and extratropical middle troposphere, zonal mean IRF kernels are up to $0.7 \mathrm{~mW} / \mathrm{m}^{2} / \mathrm{ppbv}$ with a maximum zonal mean IRF of less than $40 \mathrm{~mW} / \mathrm{m}^{2}$.

\subsection{Observational Constraint Instantaneous Radiative Forcing Bias in Models}

[48] Figures 6b-6e show the global distribution of total tropospheric IRF biases calculated in the models, based on equation (10). Figures 6b-6e reveal regionally varying total tropospheric IRF biases between -400 to $700 \mathrm{~mW} / \mathrm{m}^{2}$ in the tropical and midlatitudes covering $40^{\circ} \mathrm{S}-60^{\circ} \mathrm{N}$. The zonal mean IRF biases calculated from equation (12) and shown in Figures $7 \mathrm{~b}-7 \mathrm{e}$ equally reveal zonal mean IRF biases between -30 and $+50 \mathrm{~mW} / \mathrm{m}^{2}$, with the largest bias at the upper troposphere-lower stratosphere region.

[49] This demonstrates the ability of large concentration (or biases) of ozone to compensate for low sensitivity of OLR to ozone. These results also show the need for accurate simulation of magnitude, distribution and variability of ozone concentrations by models, especially from the middle troposphere to lower stratospheric region, where large model biases could have high climate radiative forcing impact (as shown in Figures $7 b-7 e$ and summarized by the result of equation (13) shown in Figure 8).

[50] The multimodel average plots shown in Figures $6 \mathrm{f}$ and $7 \mathrm{f}$ reveal the least total tropospheric and zonal mean IRF bias with respect to TES compared to any of the individual models, with the exception of CAM-Chem model IRF bias over certain regions. The models' ensemble mean total tropospheric IRF bias is within the range of -100 to $+300 \mathrm{~mW} / \mathrm{m}^{2}$ (Figure $6 \mathrm{f}$ ), while the zonal mean IRF bias is between -10 to $+20 \mathrm{~mW} / \mathrm{m}^{2}$ (Figure $7 \mathrm{f}$ ). The global mean multimodel average ozone IRF of $0.42 \mathrm{~W} / \mathrm{m}^{2}$ over the whole troposphere is better than 0.61 and $0.28 \mathrm{~W} / \mathrm{m}^{2}$ calculated in the ECHAM5-MOZ and GISS-PUCCINI models, respectively. The global mean tropospheric IRF calculated in AM2-Chem and CAM-Chem models are 0.41 and 0.38 , respectively. This result shows that multimodel average estimate depends on the individual models used in the averaging. In this case, the positive biases in ECHAM5MOZ northern latitudes could not fully compensate for negative biases in GISS-PUCCINI and AM2-Chem models. Also in the Southern Hemisphere, the negative biases in GISS-PUCCINI model is too low to cancel out the combination of positive biases in the AM2-Chem and ECHAM5MOZ models. This yields a multimodel mean tropospheric IRF that is not the best estimate in comparison to TES global mean tropospheric IRF of $0.37 \mathrm{~W} / \mathrm{m}^{2}$ (Figure 8).

\subsection{The Influence of TES Assimilation on Ozone and IRF in the AM2-Chem Model}

[51] The assimilation of TES v2 data into the AM2-Chem model was able to significantly improve most of the negative anomaly observed in the model at the Northern Hemisphere within the free troposphere (compare AM2-Chem plot in Figure 4b with AM2-Chem-assim plot in Figure 4g). This improvement of simulated ozone within the AM2-Chemassim model also led to a better spatial correlation $(r>0.7$ above $550 \mathrm{hPa}$, and $r \geq 0.5$ below $550 \mathrm{hPa}$ ) between AM2Chem-assim model and TES, in comparison to the spatial correlation of AM2-Chem model with TES $(r<0.55$ from the surface up to $250 \mathrm{hPa}$ ) as shown in Figure 5. However, due to low thermal contrast during the Southern Hemispheric winter season (as evidence by lower degree of freedom for signals (DOFS) in the Southern Hemisphere in comparison to Northern Hemisphere DOFs [see Parrington et al., 2008, Figure 1], assimilation of TES data does not significantly influence the Southern Hemispheric ozone concentration, and this causes the positive bias recorded there to persist (compare AM2-Chem plot in Figure 4b with AM2-Chemassim plot in Figure 4g). 
(a) TES tropos. $\mathrm{O}_{3} \mathrm{IRF}\left[\mathrm{mWm}{ }^{-2}\right]--\mathrm{Aug} 2006$

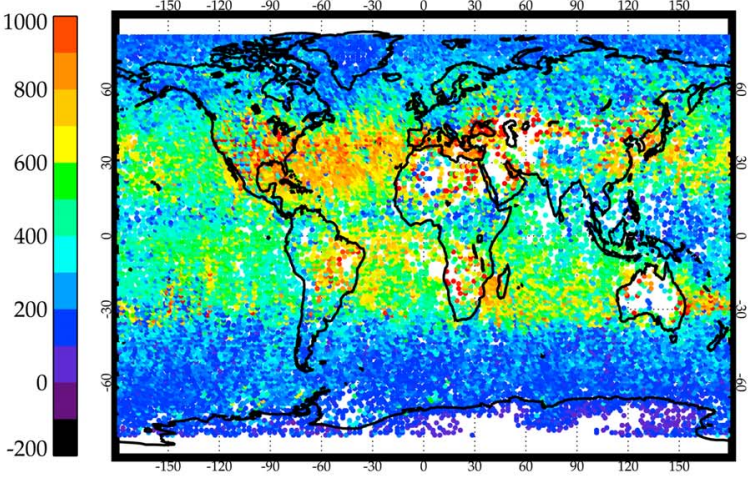

(c) CAM-Chem tropos. $\mathrm{O}_{3}$ IRF bias $\left[\mathrm{mWm}^{-2}\right]-$-Aug 2006

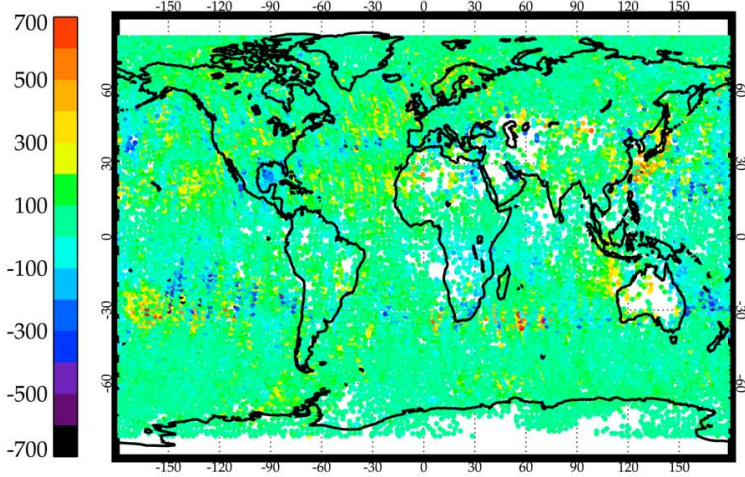

(e) GISS-PUCCINI tropos. $\mathrm{O}_{3}$ IRF bias [mWm-2]--Aug 2006

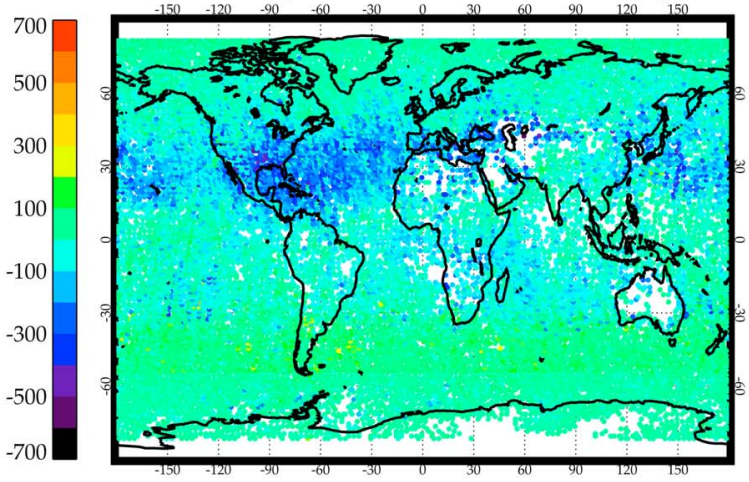

(g) AM2-Chem-assim tropos. $\mathrm{O}_{3}$ IRF bias $\left[\mathrm{mWm}^{-2}\right]--$ Aug 2006

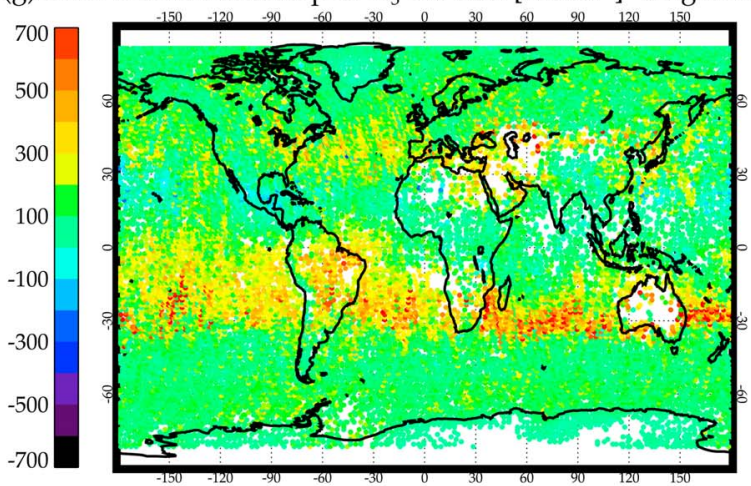

(b) AM2-Chem tropos. $\mathrm{O}_{3}$ IRF bias $\left[\mathrm{mWm}^{-2}\right]$--Aug 2006

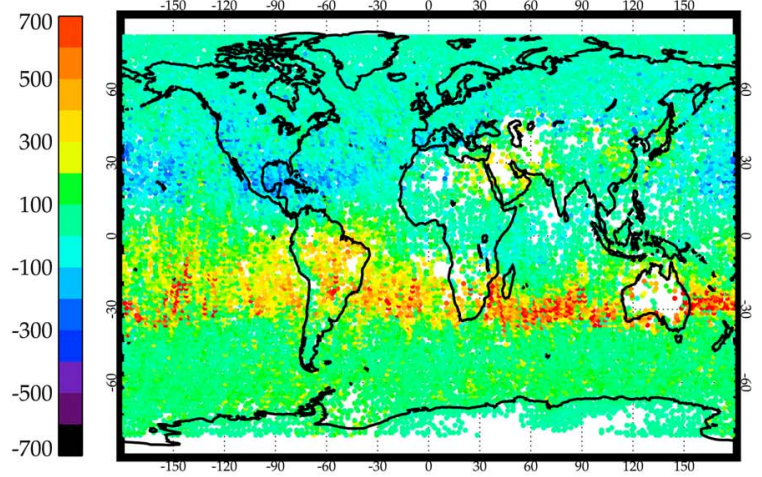

(d) ECHAM5-MOZ tropos. $\mathrm{O}_{3}$ IRF bias [mWm-2]--Aug 2006

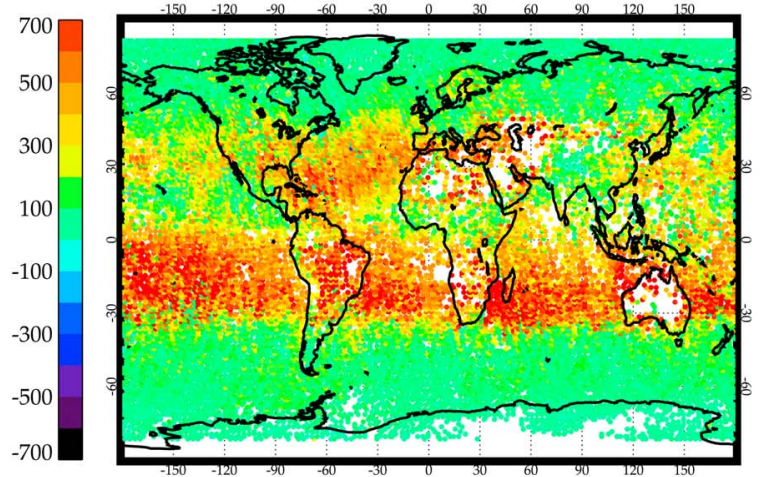

(f) Multi-model tropos. $\mathrm{O}_{3}$ IRF bias $\left[\mathrm{mWm}^{-2}\right]-$-Aug 2006

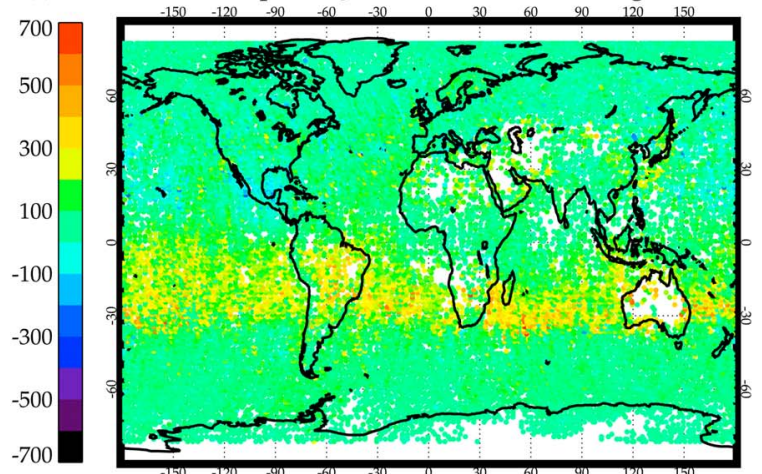

Figure 6. (a) TES total tropospheric ozone instantaneous radiative forcing and the difference in the respective models (b) AM2-Chem, (c) CAM-Chem, (d) ECHAM5-MOZ, and (e) GISS-PUCCINI under all-sky conditions in August 2006. We also show the total tropospheric ozone IRF biases in the (f) multimodel mean and (g) AM2-Chem-assim model. These plots are based on equations (9) and (10) as explained in the text. 
(a) TES all-sky IRF [mWm-2] Aug 2006

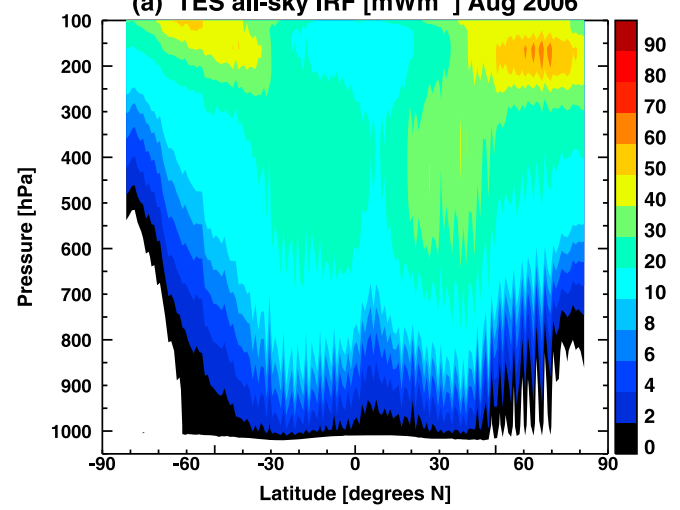

(c) CAM-Chem IRF bias $\left(\mathrm{mWm}^{-2}\right)$ Aug 2006
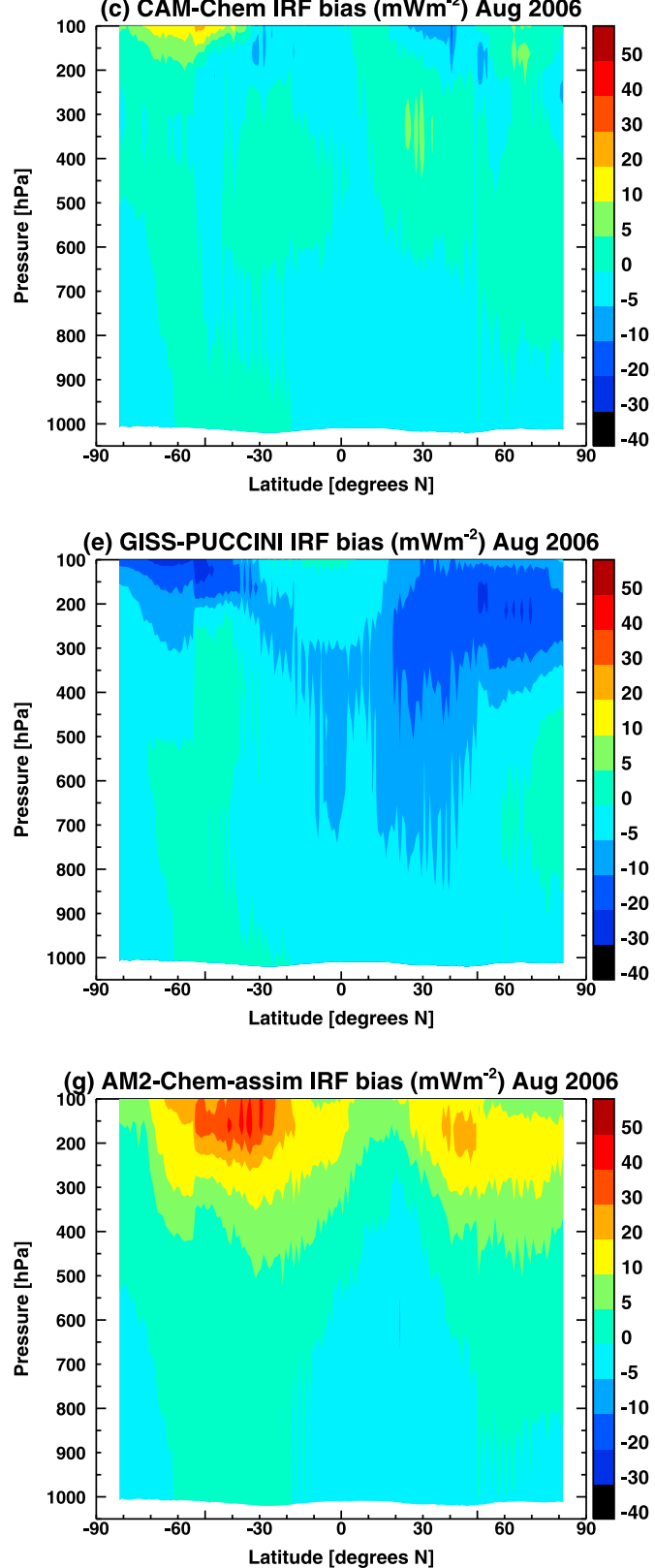

(b) AM2-Chem IRF bias $\left(\mathrm{mWm}^{-2}\right)$ Aug 2006

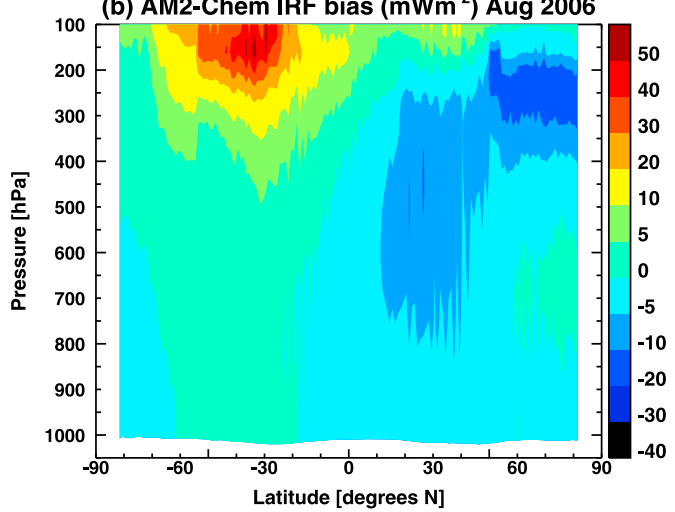

(d) ECHAM5-MOZ IRF bias (mWm-2) Aug 2006
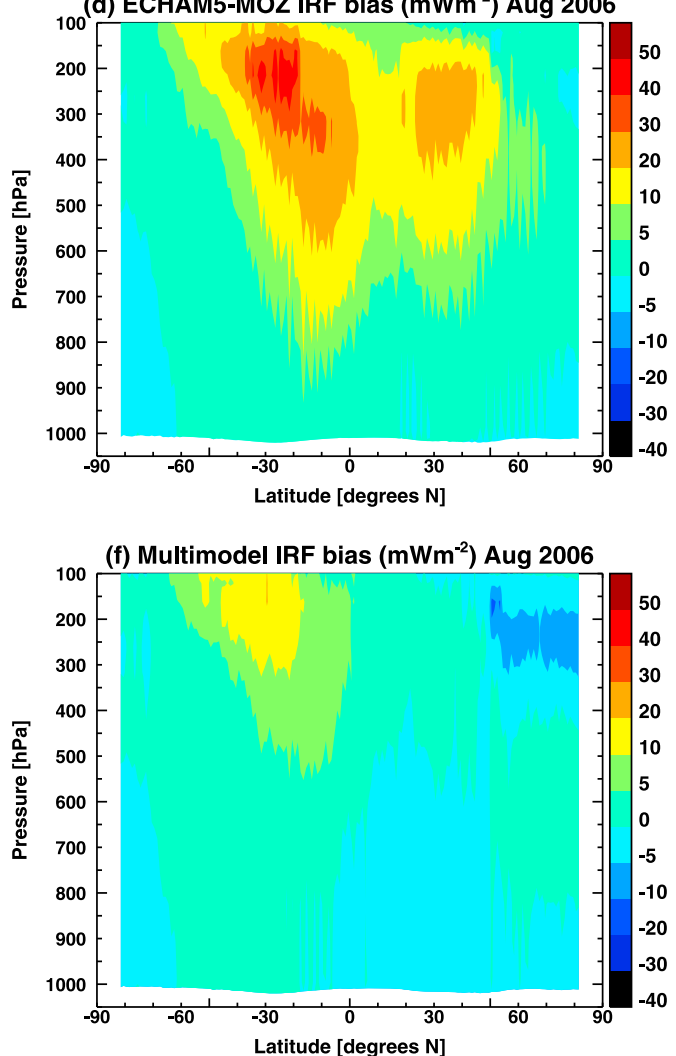

Figure 7. The zonal mean distribution of (a) TES instantaneous radiative forcing (IRF) and models IRF bias for (b) AM2-Chem, (c) CAM-Chem, (d) ECHAM5-MOZ, and (e) GISS-PUCCINI, under all-sky conditions. We also show the zonal mean (f) multimodel mean and (g) AM2-Chem-assim IRF biases. These plots are based on equations (11) and (12) as explained in the text. 


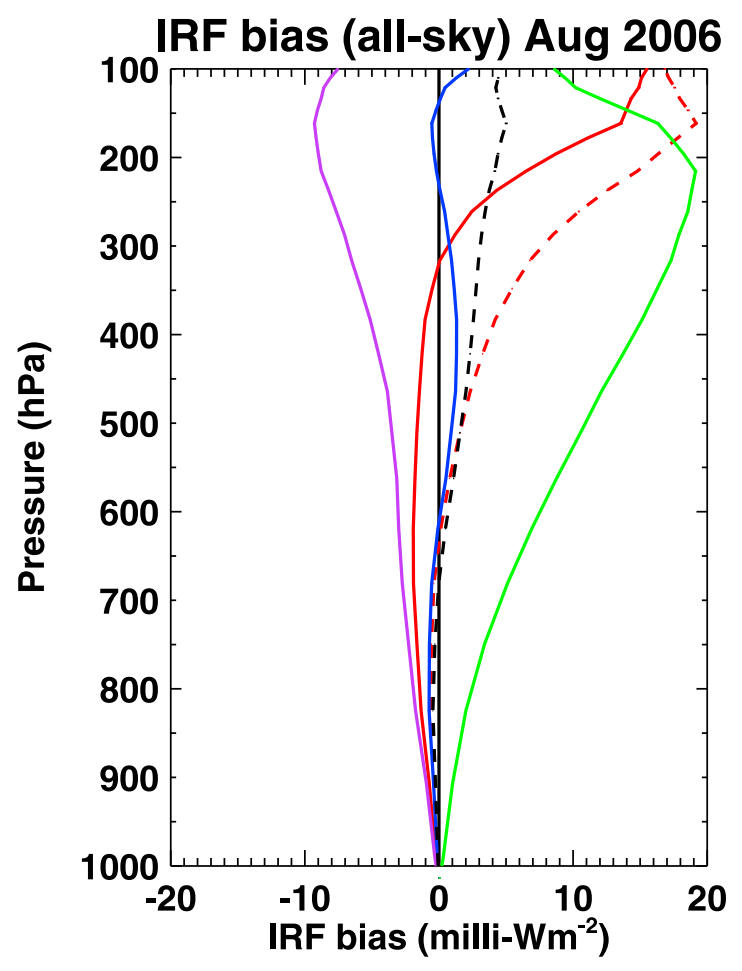

Figure 8. The vertical profile of global mean tropospheric ozone instantaneous radiative forcing for all-sky condition in August 2006. The lines show global mean IRF bias for AM2-Chem (solid red line), CAM-Chem (solid blue line), ECHAM5-MOZ (solid green line), GISS-PUCCINI (solid magenta line), multimodel mean (dashed black line), and AM2-Chem-assim (dashed red line). This plot is based on equation (13) as explained in the text.

[52] The improvement of simulated ozone within AM2Chem-assim model throughout the Northern Hemispheric free troposphere due to the assimilation of TES ozone data resulted in a significant improvement in the spatial distribution of the total tropospheric IRF bias (Figure 6g) over the entire tropical and midlatitudes of the Northern Hemisphere. Also, the zonal mean IRF bias reveals significant correction of the pronounced IRF negative biases in the middle and upper troposphere of the midlatitudes and the polar region (Figure $7 \mathrm{~g}$ ).

[53] Comparing the models' ensemble mean and AM2Chem-assim total tropospheric IRF biases shown in Figure $6 \mathrm{f}$ and $6 \mathrm{~g}$, respectively, demonstrates the potential of chemical data assimilation to reduce uncertainties in modeled tracer distributions [Parrington et al., 2008], with consequence for radiative forcing calculations.

\section{Summary and Conclusions}

[54] We have presented an evaluation of the instantaneous radiative forcing of tropospheric ozone predicted by four state-of-the-art global chemistry climate models, which are AM2-Chem, CAM-Chem, ECHAM5-MOZ and GISSPUCCINI in August 2006. These vertical and spatial instantaneous radiative forcing discrepancies between models and TES observation were calculated through all- sky instantaneous radiative forcing kernels, which were directly estimated from TES top-of-the-atmosphere outgoing longwave radiative flux. The instantaneous radiative forcing derived by applying TES kernels is different from the tropospheric ozone radiative forcing presented in the IPCC [Forster et al., 2007] because it does not include the shortwave forcing of tropospheric ozone, which is not negligible especially over the polar region.

[55] The evaluation of tropospheric ozone concentrations simulated by each of the models against TES were performed, and we show that each of the models has discrepancies with respect to TES, both in capturing the magnitude and spatial distribution of ozone. In the lower and middle troposphere, the models have the largest disagreement with TES over the tropical and the midlatitudes regions, where they show a zonal mean bias of up to $\pm 40 \mathrm{ppbv}$. In the UTLS region, the models show zonal mean absolute bias of more than \pm 30 ppbv. Our initial analysis with GISS-PUCCINI and ECHAM5-MOZ models reveal that during this particular month, prescribed meteorology of NCEP and ECMWF are partially responsible for the anomalous UTLS ozone bias, and this may explain why CAM-Chem shows a relatively low bias in comparison to other models, since it includes no nudging. Further study is needed to understand the prevailing circumstances and triggers of this extrinsic influence on the simulation of chemical composition.

[56] Our results show the necessity for accurate simulation of both magnitude and spatial distribution of ozone within models, since large concentrations of ozone and ozone biases could compensate for low sensitivity of OLR to ozone (that is, low IRF kernels), to produce relatively large instantaneous radiative forcing, as seen around the tropopause of the polar region. We calculate a spatially varying total tropospheric IRF bias of between -400 to $+700 \mathrm{~mW} / \mathrm{m}^{2}$ over the entire tropical and midlatitudes regions. The zonal mean ozone IRF bias also ranges from -30 to $+50 \mathrm{~mW} / \mathrm{m}^{2}$, with the largest bias in the upper troposphere and lower stratosphere. The global mean multimodel average ozone IRF of $0.42 \mathrm{~W} / \mathrm{m}^{2}$ over the whole troposphere does not provide the best estimate in comparison to TES global mean tropospheric ozone IRF of $0.37 \mathrm{~W} / \mathrm{m}^{2}$ in August 2006, due to inability of AM2-Chem, ECHAM5-MOZ and GISS-PUCCINI models to completely cancel out their opposing biases.

[57] The improved tropospheric ozone distribution in AM2-Chem following assimilation, as shown by Parrington et al. [2008], leads to a more comparable ozone distribution and IRF relative to those derived directly from TES measurements. The resulting IRF biases calculated in the AM2Chem with assimilation are comparable to low bias recorded in the multimodel IRF. This demonstrates the potential of chemical data assimilation to reduce uncertainties in modeled tracer distributions and their subsequent impact on radiative forcing calculations.

[58] This paper demonstrates the application of TES instantaneous radiative forcing kernels under all-sky conditions in August 2006. The kernels provide a unique way for an observationally constrained evaluation of ozone calculated by models. The kernels also reveal the radiative impact of differences in model-predicted ozone concentrations. The availability of spatial and vertical information for modelers has an immediate consequence for exposing regions necessary for model improvements. 
[59] Acknowledgments. We appreciate comments from Luca Pozzoli at the Joint Research Centre, Italy; Martin G. Schultz at ICG-2, Research Centre, Jülich, Germany; Larry Horowitz at NOAA Geophysical Fluid Dynamics Laboratory, Princeton, New Jersey, United States; and colleagues in the Tropospheric Emission Spectrometer group, Jet Propulsion Laboratory, California Institute of Technology, Pasadena, California, United States. A.M.A. thanks Heidi Lorenz-Wirzba of the supercomputing group at JPL and also Louis Kornblueh, Johann Feichter, Uwe Schulzweida, Erich Roeckner, and Monika Esch of Max Planck Institute for Meteorology, Hamburg, Germany, for their support at different stages of porting, compiling, and running ECHAM5-MOZ on the JPL supercomputer. The research described in this paper was partially carried out at the Jet Propulsion Laboratory, California Institute of Technology, under a NASA ROSES contract received by K.W.B. and H.M.W. United States government sponsorship acknowledged.

\section{References}

Aghedo, A. M. (2007), The impact of African air pollution: A global chemistry climate model study, Ph.D. thesis, Univ. of Hamburg, Hamburg, Germany. Aghedo, A. M., M. G. Schultz, and S. Rast (2007), The influence of African air pollution on regional and global tropospheric ozone, Atmos. Chem. Phys., 7, 1193-1212.

Aghedo, A. M., S. Rast, and M. G. Schultz (2008), Sensitivity of tracer transport to model resolution, forcing data and tracer lifetime in the general circulation model ECHAM5, Atmos. Chem. Phys. Discuss., 8, 137-160.

Beer, R., T. Glavich, and D. Rider (2001), Tropospheric Emission Spectrometer for the Earth Observing System's Aura satellite, Appl. Opt., 40, 2356-2367.

Berntsen, T. K., G. Myhre, F. Stordal, and I. S. A. Isaksen (2000), Time evolution of tropospheric ozone and its radiative forcing, J. Geophys. Res., 105(D7), 8915-8930.

Bian, H., and M. Prather (2002), Fast-J2: Accurate simulations of photolysis in global climate models, J. Atmos. Chem., 41, 281-296.

Bowman, K. W., J. Worden, T. Steck, H. M. Worden, S. Clough, and C. Rodgers (2002), Capturing time and vertical variability of tropospheric ozone: A study using TES nadir retrievals, J. Geophys. Res. 107(D23), 4723, doi:10.1029/2002JD002150.

Bowman, K. W., et al. (2006), Tropospheric emission spectrometer: Retrieval method and error analysis, IEEE Trans. Geosci. Remote Sensing, 44(5), 1295-1307.

Bowman, K. W., D. B. A. Jones, J. A. Logan, H. Worden, F. Boersma, R. Chang, S. Kulawik, G. Osterman, P. Hamer, and J. Worden (2009), The zonal structure of tropical $\mathrm{O}_{3}$ and $\mathrm{CO}$ as observed by the Tropospheric Emission Spectrometer in November 2004 Part 2: Impact of surface emissions on $\mathrm{O}_{3}$ and its precursors, Atmos. Chem. Phys., 9, 3563-3582.

Brasseur, G. P., X. Tie, P. J. Rasch, and F. Lefevre (1997), A three-dimensional simulation of the Antarctic ozone hole: Impact of anthropogenic chlorine on the lower stratosphere and upper troposphere, J. Geophys. Res., 102(D7), 8909-8930.

Butkovskaya, N., A. Kukui, and G. Le Bras (2007), $\mathrm{HNO}_{3}$ forming channel of the $\mathrm{HO}_{2}+\mathrm{NO}$ reaction as a function of pressure and temperature in the ranges of 72-600 Torr and 223-323 K, J. Phys. Chem. A, 111, 9047-9053.

Clough, S. A., J. R. Worden, P. D. Brown, M. W. Shephard, C. P. Rinsland, and R. Beer (2002), Retrieval of tropospheric ozone from simulations of nadir spectral radiances from space, J. Geophys. Res., 107(D21), 4589, doi:10.1029/2001JD001307.

Clough, S., et al. (2006), Forward model and Jacobians for Tropospheric Emission Spectrometer retrievals, IEEE Trans. Geosci. Remote Sensing, 44(5), 1308-1323.

Collins, W. D., et al. (2006), The Community Climate System Model version 3 (CCSM3), J. Clim., 19, 2122-2143, doi:10.1175/JCLI3761.1.

Dentener, F., et al. (2006), Nitrogen and sulphur deposition on regional and global scales: A multimodel evaluation, Global Biogeochem. Cycles, 20, GB4003, doi:10.1029/2005GB002672.

Fishman, J., et al. (2008), Remote sensing of tropospheric pollution from space, Bull. Am. Meteorol. Soc., 89, 805-821.

Forster, P., et al. (2007), Changes in atmospheric constituents and in radiative forcing, in Climate Change 2007: The Physical Science Basis. Contribution of Working Group I to the Fourth Assessment Report of the Intergovernmental Panel on Climate Change, edited by J. T. Houghton et al., pp. 131-217, Cambridge Univ. Press, Cambridge, U. K.

Ganzeveld, L. (2001), Surface-atmosphere trace gas and aerosol exchanges on the global scale, Ph.D. thesis, Univ. of Utrecht, Utrecht, Netherlands.

Gauss, M., et al. (2006), Radiative forcing since preindustrial times due to ozone change in the troposphere and the lower stratosphere, Atmos. Chem. Phys., 6, 575-599.
Gery, M., G. Whitten, J. Killus, and M. Dodge (1989), A photochemical kinetics mechanism for urban and regional scale computer modeling, J. Geophys. Res., 94(D10), 12,925-12,956.

GFDL GAMDT (2003), The new GFDL global atmosphere and land model AM2-LM2: Evaluation with prescribed SST simulations, J. Clim., 17, 4641-4673.

Grewe, V., D. Brunner, M. Dameris, J. L. Grenfell, R. Hein, D. Shindell, and J. Staehelin (2001), Origin and variability of upper tropospheric nitrogen oxides and ozone at northern mid-latitudes, Atmos. Environ., 35, 3421-3433.

Guenther, A., T. Karl, P. Harley, C. Wiedinmyer, P. I. Palmer, and C. Geron (2006), Estimates of global terrestrial isoprene emissions using MEGAN (Model of Emissions of Gases and Aerosols from Nature), Atmos. Chem. Phys., 6, 3181-3210.

Hansen, J., M. Sato, and R. Ruedy (1997), Radiative forcing and climate response, J. Geophys. Res., 102(D6), 6831-6864.

Hanson, D., and K. Mauersberger (1988), Laboratory studies of the nitric acid tridydrate: Implications for the south polar stratosphere, Geophys. Res. Lett., 15(8), 855-858.

Hauglustaine, D. A., and G. P. Brasseur (2001), Evolution of tropospheric ozone under anthropogenic activities and associated radiative forcing of climate, J. Geophys. Res., 106(D23), 32,337-32,360.

Hauglustaine, D. A., L. Emmons, M. Newchurch, G. Brasseur, T. Takao, K. Matsubara, J. Johnson, B. Ridley, J. Stith, and J. Dye (2001), On the role of lightning $\mathrm{NO}_{x}$ in the formation of tropospheric ozone plumes: A global model perspective, J. Atmos. Chem., 38, 277-294.

Haywood, J. M., M. D. Schwarzkopf, and V. Ramaswamy (1998), Estimates of radiative forcing due to modeled increases in tropospheric ozone, J. Geophys. Res., 103(D14), 16,999-17,007.

Horowitz, L. W., et al. (2003), A global simulation of tropospheric ozone and related tracers: Description and evaluation of MOZART, version 2, J. Geophys. Res., 108(D24), 4784, doi:10.1029/2002JD002853.

Houweling, S., F. Dentener, and J. Lelieveld (1998), The impact of nonmethane hydrocarbon compounds on tropospheric photochemistry, J. Geophys. Res., 103(D9), 10,673-10,696.

Jeuken, A. B. M., P. C. Siegmund, L. C. Heijboer, J. Feichter, and L. Bengtson (1996), On the potential of assimilating meteorological analysis in a climate model for the purpose of model validation, J. Geophys. Res., 101(D12), 16,939-16,950.

Joiner, J., M. R. Schoeberl, A. P. Vasilkov, L. Oreopoulos, S. Platnick, N. J. Livesey, and P. F. Levelt (2009), Accurate satellite-derived estimates of the tropospheric ozone impact on the global radiation budget, Atmos. Chem. Phys., 9, 4447-4465.

Jones, D. B. A., K. W. Bowman, P. I. Palmer, J. R. Worden, D. J. Jacob, R. N. Hoffman, I. Bey, and R. M. Yantosca (2003), Potential of observations from the Tropospheric Emission Spectrometer to constrain continental sources of carbon monoxide, J. Geophys. Res., 108(D24), 4789, doi:10.1029/2003JD003702.

Jones, D. B. A., K. W. Bowman, J. A. Logan, C. L. Heald, J. Liu, M. Luo, J. Worden, and J. Drummond (2009), The zonal structure of tropical $\mathrm{O}_{3}$ and $\mathrm{CO}$ as observed by the Tropospheric Emission Spectrometer in November 2004-Part 1: Inverse modeling of CO emissions, Atmos. Chem. Phys., 9, 3547-3562.

Kalnay, E., et al. (1996), The NCEP/NCAR 40-year reanalysis project, Bull. Am. Meteorol. Soc., 77, 437-471.

Kinnison, D. E., et al. (2007), Sensitivity of chemical tracers to meteorological parameters in the MOZART-3 chemical transport model, J. Geophys. Res., 112, D20302, doi:10.1029/2006JD007879.

Lacis, A., D. J. Wuebbles, and J. A. Logan (1990), Radiative forcing of climate by changes in the vertical distribution of ozone, J. Geophys. Res., 95(D7), 9971-9981.

Lack, D. A., X. X. Tie, N. D. Bofinger, A. N. Wiegand, and S. Madronich (2004), Seasonal variability of secondary organic aerosol: A global modeling study, J. Geophys. Res., 109, D03203, doi:10.1029/2003JD003418.

Lamarque, J.-F., D. E. Kinnison, P. G. Hess, and F. M. Vitt (2008), Simulated lower stratospheric trends between 1970 and 2005: Identifying the role of climate and composition changes, J. Geophys. Res., 113, D12301, doi:10.1029/2007JD009277.

Lamarque, J. F., et al. (2010), Historical (1850-2000) gridded anthropogenic and biomass burning emissions of reactive gases and aerosols: Methodology and application, Atmos. Chem. Phys. Discuss., 10, 4963-5019.

Lelieveld, J., and P. J. Crutzen (1990), Influences of cloud photochemical processes on tropospheric ozone, Nature, 343, 227-233, doi:10.1038/ $343227 \mathrm{a} 0$.

Loeb, N. G., N. M. Smith, S. Kato, W. F. Miller, S. K. Gupta, P. Minnis, and B. A. Wielicki (2003), Angular distribution models for top-of-atmosphere radiative flux estimation from the Clouds and the Earth's Radiant Energy System instrument on the Tropical Rainfall Measuring Mission Satellite. Part I: Methodology, J. Appl. Meteorol., 42, 240-265. 
Madronich, S., and S. Flocke (1999), The role of solar radiation in atmospheric chemistry, in The Handbook of Environmental Chemistry, vol. 2, part 1, edited by P. Boule, pp. ?-?, Springer, Berlin.

Marenco, A., H. Gouget, P. Nédélec, J.-P. Pagés, and F. Karcher (1994), Evidence of a long-term increase in tropospheric ozone from Pic du Midi data series: Consequences: Positive radiative forcing, J. Geophys. Res. 99(D8), 16,617-16,632.

Martin, R. V., D. J. Jacob, J. A. Logan, J. M. Ziemke, and R. Washington (2000), Detection of a lightning influence on tropical tropospheric ozone, Geophys. Res. Lett., 27(11), 1639-1642.

Mickley, L. J., D. J. Jacob, and D. Rind (2001), Uncertainty in preindustrial abundance of tropospheric ozone: Implications for radiative forcing calculations, J. Geophys. Res., 106(D4), 3389-3399.

Naik, V., D. Mauzerall, L. Horowitz, M. D. Schwarzkopf, V. Ramaswamy, and M. Oppenheimer (2005), Net radiative forcing due to changes in regional emissions of tropospheric ozone precursors, J. Geophys. Res., 110, D24306, doi:10.1029/2005JD005908

Nassar, R., et al. (2008), Validation of Tropospheric Emission Spectrometer (TES) nadir ozone profiles using ozonesonde measurements, J. Geophys. Res., 113, D15S17, doi:10.1029/2007JD008819.

Osterman, G., et al. (2008), Validation of Tropospheric Emission Spectrometer (TES) measurements of the total, stratospheric and tropospheric column abundance of ozone, J. Geophys. Res., 113, D15S16, doi:10.1029/2007JD008801

Osterman, G., et al. (2009), Tropospheric Emission Spectrometer (TES) L2 data user's guide, Tech. Rep. V4.00, Jet Propul. Lab., Calif. Inst. of Technol., Pasadena.

Parrington, M., D. B. A. Jones, K. W. Bowman, L. W. Horowitz, A. M. Thompson, D. W. Tarasick, and J. C. Witte (2008), Estimating the summertime tropospheric ozone distribution over North America through assimilation of observations from the TroposphericEmission Spectrometer, J. Geophys. Res., 113, D18307, doi:10.1029/2007JD009341.

Parrington, M., D. B. A. Jones, K. W. Bowman, A. M. Thompson, D. W. Tarasick, J. Merrill, S. J. Oltmans, T. Leblanc, J. C. Witte, and D. B. Millet (2009), Impact of the assimilation of ozone from the Tropospheric Emission Spectrometer on surface ozone across North America, Geophys. Res. Lett., 36, L04802, doi:10.1029/2008GL036935.

Pickering, K. E., Y. Wang, W. Tao, C. Price, and J.-F. Muller (1998) Vertical distributions of lightning $\mathrm{NO}_{x}$ for use in regional and global chemical transport models, J. Geophys. Res., 103(D23), 31,203-31,216.

Prather, M. J. (1986), Numerical advection by conservation of secondorder moments, J. Geophys. Res., 91(D6), 6671-6681.

Price, C., J. Penner, and M. Prather (1997), $\mathrm{NO}_{x}$ from lightning: 1. Global distribution based on lightning physics, J. Geophys. Res., 102(D5), 5929-5941.

Ramanathan, V., R. D. Cess, E. F. Harrison, P. Minnis, B. R. Barkstrom E. Ahmad, and D. Hartmann (1989), Cloud-radiative forcing and climate: Results from the Earth Radiation Budget experiment, Science, 243, 57-63.

Ramaswamy, V., et al. (2001), Radiative forcing of climate change, in Climate Change 2001: The Scientific Basis. Contribution of Working Group I to the Third Assessment Report of Intergovernmental Panel on Climate Change, edited by J. T. Houghton et al., pp. 349-416, Cambridge Univ. Press, Cambridge, U. K

Randel, W. J., and F. Wu (1999), A stratospheric ozone trends data set for global modeling studies, Geophys. Res. Lett., 26(20), 3089-3092.

Rayner, N. A., D. E. Parker, E. B. Horton, C. K. Folland, L. V. Alexander, D. P. Rowell, E. C. Kent, and A. Kaplan (2003), Global analyses of sea surface temperature, sea ice, and night marine air temperature since the late nineteenth century, J. Geophys. Res., 108(D14), 4407, doi:10.1029/ 2002JD002670.

Richards, N. A. D., G. B. Osterman, E. V. Browell, J. W. Hair, M. Avery, and Q. Li (2008), Validation of Tropospheric Emission Spectrometer ozone profiles with aircraft observations during the Intercontinenta Chemical Transport Experiment-B, J. Geophys. Res., 113, D16S29, doi:10.1029/2007JD008815

Rodgers, C. D. (2000), Inverse Methods for Atmospheric Sounding: Theory and Practice, World Sci., River Edge, N. J.

Roeckner, E., et al. (2003), The atmospheric general circulation model ECHAM5, part I: Model description, Rep. 349, Max Planck Inst. for Meteorol., Hamburg, Germany.

Sander, S. P., et al. (2000), Chemical kinetics and photochemical data for use in stratospheric modeling, Publ. 00-003, Jet Propul. Lab., Pasadena, Calif.

Sander, S. P., et al. (2003), Chemical kinetics and photochemical data for use in atmospheric studies, Publ. 02-25, Jet Propul. Lab., Pasadena, Calif.

Sander, S. P., et al. (2006), Chemical kinetics and photochemical data for use in atmospheric studies, Publ. 06-2, Jet Propul. Lab., Pasadena, Calif.

Schmidt, G. A., et al. (2006), Present day atmospheric simulations using GISS ModelE: Comparison to in-situ, satellite and reanalysis data, J. Clim., 19, 153-192.
Schultz, M., S. Rast, M. van het Bolscher, T. Pulles, R. Brand, J. Pereira B. Mota, A. Spessa, S. Dalsøren, T. van Nojie, and S. Szopa (2007), Emission data sets and methodologies for estimating emissions, RETRO Proj. Rep. D1-6, Eur. Union, Brussels. (Available at http://retro.enes.org/ reports/D1-6 final.pdf)

Shindell, D. T., G. Faluvegi, and N. Bell (2003), Preindustrial-to-present-day radiative forcing by tropospheric ozone from improved simulations with the GISS chemistry-climate GCM, Atmos. Chem. Phys., 3 1675-1702.

Shindell, D. T., et al. (2006a), Multimodel simulations of carbon monoxide: Comparison with observations and projected near-future changes, J. Geophys. Res., 111, D19306, doi:10.1029/2006JD007100.

Shindell, D. T., G. Faluvegi, N. Unger, E. Aguilar, G. A. Schmidt, D. Koch, S. E. Bauer, and R. L. Miller (2006b), Simulations of preindustrial, present-day, and 2100 conditions in the NASA GISS composition and climate model G-PUCCINI, Atmos. Chem. Phys., 6, 4427-4459.

Soden, B. J., I. M. Held, R. Colman, K. M. Shell, J. T. Kiehl, and C. A Shields (2008), Quantifying climate feedbacks using radiative kernels, J. Clim., 21, 3504-3520.

Stevenson, D. S., et al. (2006), Multi-model ensemble simulations of present-day and near-future tropospheric ozone, J. Geophys. Res., 111 D08301, doi:10.1029/2005JD006338.

Stier, P., et al. (2005), The aerosol-climate model ECHAM5-HAM, Atmos. Chem. Phys., 5, 1125-1156.

Thompson, A. M., et al. (2007a), Intercontinental Chemical Transport Experiment Ozonesonde Network Study (IONS) 2004: 1. Summertime upper troposphere/lower stratosphere ozone over northeastern North America, J. Geophys. Res., 112, D12S12, doi:10.1029/2006JD007441.

Thompson, A. M., et al. (2007b), Intercontinental Chemical Transport Experiment Ozonesonde Network Study (IONS) 2004: 2. Tropospheric ozone budgets and variability over northeastern North America, J. Geophys. Res., 112, D12S13, doi:10.1029/2006JD007670.

van Noije, T. P. C., H. J. Eskes, M. van Weele, and P. F. J. van Velthoven (2004), Implications of the enhanced Brewer-Dobson circulation in European Centre for Medium-Range Weather Forecasts reanalysis ERA-40 for the stratosphere-troposphere exchange of ozone in global chemistry transport models, J. Geophys. Res., 109, D19308, doi:10.1029/2004JD004586.

Volz, A., and D. Kley (1988), Evaluation of the Montsouris series of ozone measurements made in the nineteenth century, Nature, 332, 240-242, doi:10.1038/332240a0.

Wang, Y., and D. J. Jacob (1998), Anthropogenic forcing on tropospheric ozone and $\mathrm{OH}$ since preindustrial times, J. Geophys. Res., 103(D23), 31,123-31,135.

Wang, Y., D. Jacob, and J. A. Logan (1998), Global simulation of tropospheric $\mathrm{O}_{3}-\mathrm{NO}_{x}$-hydrocarbon chemistry: 3. Origin of tropospheric ozone and its effects on nonmethane hydrocarbons, J. Geophys. Res., 103(D9), $10,757-10,767$

Worden, H. M., et al. (2007), Comparisons of Tropospheric Emission Spectrometer (TES) ozone profiles to ozonesondes: Methods and initial results, J. Geophys. Res., 112, D03309, doi:10.1029/2006JD007258.

Worden, H. M., K. W. Bowman, J. R. Worden, A. Eldering, and R. Beer (2008), Satellite measurements of the clear-sky greenhouse effect from tropospheric ozone, Nat. Geosci., 1, 305-308, doi:10.1038/ngeo182.

Worden, J., S. S. Kulawik, M. Shepard, S. Clough, H. Worden, K. Bowman, and A. Goldman (2004), Predicted errors of Tropospheric Emission Spectrometer nadir retrievals from spectral window selection, J. Geophys. Res., 109, D09308, doi:10.1029/2004JD004522.

World Meteorological Organization (1957), Meteorology-A three-dimensional science: Second session of the Commission for Aerology, WMO Bull., 4, 134-138.

Zhu, B., H. Xiao, M. Huang, and Z. Li (2001), Numerical study of cloud effects on tropospheric ozone, Water Air Soil Pollut., 129(1), 199-216, doi:10.1023/A:1010368229728.

A. M. Aghedo, K. W. Bowman, and S. S. Kulawik, Jet Propulsion Laboratory, California Institute of Technology, MS 183-601, 4800 Oak Grove Dr., Pasadena, CA 91109, USA. (adetutu.m.aghedo@jpl.nasa.gov) G. Faluvegi and D. T. Shindell, NASA Goddard Institute for Space Studies, 2880 Broadway, New York, NY 10025, USA.

D. B. A. Jones, Department of Physics, University of Toronto, $60 \mathrm{St}$. George St., Toronto, ON M5S 1A7, Canada.

J.-F. Lamarque and H. M. Worden, Atmospheric Chemistry Division, National Center for Atmospheric Research, P. O. Box 3000, Boulder, CO 80307-3000, USA

M. Parrington, School of Geosciences, University of Edinburgh, King's Buildings, West Mains Road, Edinburgh EH9 3JN, UK.

S. Rast, Max Planck Institute for Meteorology, Bundesstr. 53, D-20146, Hamburg, Germany. 